\title{
Simultaneous Physiologically Based Pharmacokinetic (PBPK) Modeling of Parent and Active Metabolites to Investigate Complex CYP3A4 Drug-Drug Interaction Potential: A Case Example of Midostaurin ${ }^{[}$
}

\author{
Helen Gu, Catherine Dutreix, Sam Rebello, Taoufik Ouatas, Lai Wang, Dung Yu Chun, \\ Heidi J. Einolf, and Handan He
}

Novartis Pharmaceuticals Corporation, East Hanover, New Jersey (H.G., S.R., L.W., D.Y.C., H.J.E., H.H.); Novartis Pharmaceuticals Corporation, Basel, Switzerland (C.D., T.O.); and Insmed Inc., Bridgewater, New Jersey (D.Y.C.)

Received August 15, 2017; accepted November 3, 2017

\begin{abstract}
Midostaurin (PKC412) is being investigated for the treatment of acute myeloid leukemia (AML) and advanced systemic mastocytosis (advSM). It is extensively metabolized by CYP3A4 to form two major active metabolites, CGP52421 and CGP62221. In vitro and clinical drug-drug interaction (DDI) studies indicated that midostaurin and its metabolites are substrates, reversible and timedependent inhibitors, and inducers of CYP3A4. A simultaneous pharmacokinetic model of parent and active metabolites was initially developed by incorporating data from in vitro, preclinical, and clinical pharmacokinetic studies in healthy volunteers and in patients with AML or advSM. The model reasonably predicted changes in midostaurin exposure after single-dose administration with ketoconazole (a 5.8-fold predicted versus 6.1-fold observed increase) and rifampicin ( $90 \%$ predicted versus $94 \%$ observed reduction) as well as changes in midazolam exposure (1.0
\end{abstract}

predicted versus 1.2 observed ratio) after daily dosing of midostaurin for 4 days. The qualified model was then applied to predict the DDI effect with other CYP3A4 inhibitors or inducers and the DDI potential with midazolam under steady-state conditions. The simulated midazolam area under the curve ratio of 0.54 and an accompanying observed 1.9-fold increase in the CYP3A4 activity of biomarker $4 \beta$-hydroxycholesterol indicated a weak-to-moderate CYP3A4 induction by midostaurin and its metabolites at steady state in patients with advSM. In conclusion, a simultaneous parentand-active-metabolite modeling approach allowed predictions under steady-state conditions that were not possible to achieve in healthy subjects. Furthermore, endogenous biomarker data enabled evaluation of the net effect of midostaurin and its metabolites on CYP3A4 activity at steady state and increased confidence in DDI predictions.

\section{Introduction}

Midostaurin is a potent kinase inhibitor of FMS- like tyrosine kinase 3 (FLT3), KIT (including D816V and Y mutants), platelet-derived growth factor receptor $\beta$, vascular endothelial growth factor receptor 2, fibroblast growth factor receptor, and protein kinase C. FLT3 mutations occur in approximately $30 \%$ of patients with acute myeloid leukemia (AML). Midostaurin is equally active against FLT3 with internal tandem duplications (ITDs) and with tyrosine kinase domain mutations and has been shown to inhibit other kinases implicated in diseases, including

Funding for this project, including medical editorial assistance, was provided by Novartis. Laboratories of origin for this study are the same as the affiliations.

https://.doi.org/10.1124/dmd.117.078006.

S This article has supplemental material available at dmd.aspetjournals.org.
KIT in advanced systemic mastocytosis (advSM) (AndrejauskasBuchdunger and Regenass, 1992; Fabbro et al., 2000; Propper et al., 2001; Weisberg et al., 2002; Gotlib et al., 2005; Stone et al., 2005; Barry et al., 2007). Midostaurin is in clinical development for treatment of FLT3-mutated AML and advSM (Stone et al., 2005; Fischer et al., 2010; Gallogly and Lazarus, 2016; Gotlib et al., 2016). Based primarily on the phase 3 RATIFY clinical study (Stone et al., 2015), the US Food and Drug Administration granted approval to midostaurin in April 2017.

Midostaurin is rapidly and almost completely absorbed in humans after oral administration (Yin et al., 2008; Dutreix et al., 2013) and is highly distributed. Midostaurin is extensively metabolized by CYP3A4 to form its two metabolites, CGP52421 (7-hydroxylation, epimer 2) and CGP62221 (O-demethylation) (Yin et al., 2008; Wang et al., 2008). Elimination is primarily through fecal excretion, mostly as metabolites. CGP52421 and CGP62221 have also been identified as being pharmacologically active

ABBREVIATIONS: $4 \beta \mathrm{HC}, 4 \beta$-hydroxycholesterol; ADME, absorption, distribution, metabolism, and excretion; advSM, advanced systemic mastocytosis; AGP, $\alpha 1$-acid glycoprotein; AML, acute myeloid leukemia; AUC, area under the curve; Caco-2, continuous heterogeneous human epithelial colorectal adenocarcinoma cell line; $C L$, clearance; $C L / F$, apparent oral clearance; $\mathrm{CL}_{\text {int }}$, intrinsic clearance; $D D I$, drug-drug interaction; $\mathrm{F}_{\mathrm{a}}$, fraction of dose absorbed; $F_{g}$, fraction of the dose that escapes presystemic intestinal first-pass elimination; FLT3, fms-like tyrosine kinase 3; FMl, final market image; fu gut, fraction of unbound drug in the gut; GM, geometric mean; GMR, geometric mean ratio; HLM, human liver microsome; inf, infinity; ITD, internal tandem duplication; IL-6, interleukin 6; PBPK, physiologically based pharmacokinetic; PK, pharmacokinetics; Pop, population; $\mathrm{Q}$, intercompartmental clearance; TDI, time-dependent inhibitor; $t_{\text {lag }}$, lag time; $\mathrm{V}_{\mathrm{sac}}$, volume of distribution for the single adjustable compartment; $\mathrm{V}_{\mathrm{ss}}$, volume of distribution at steady state. 
against cells expressing FLT3-ITDs and KIT D816V (Propper et al., 2001). Midostaurin ( $\mathrm{EC}_{50}$ of cytotoxicity response of 39 and $47 \mathrm{nM}$ for FLT3ITDs and KIT D816V, respectively) and CGP62221 ( $\mathrm{EC}_{50}$ of cytotoxicity response of 30 and $70 \mathrm{nM}$ for FLT3-ITDs and KIT D816V, respectively) showed similar potency (Levis et al., 2006), whereas CGP52421 showed an average approximately 10 -fold reduced potency $\left(\mathrm{EC}_{50}\right.$ of cytotoxicity response of 656 and $233 \mathrm{nM}$ for FLT3-ITDs and KIT D816V, respectively). Both metabolites were also found to be CYP3A4 substrates (Dutreix et al., 2013). Therefore, drug-drug interactions (DDIs) can result in exposure alterations of midostaurin and its metabolites when coadministered with drugs that inhibit or induce CYP3A4. Furthermore, midostaurin and its two active metabolites were reversible and timedependent inhibitors (TDIs) and inducers of CYP3A4 in vitro. These mixed CYP3A4 interactions can potentially affect the exposure of victim drugs when coadministered with drugs that are sensitive CYP3A4 substrates (e.g., midazolam). Due to these complex DDI mechanisms, midostaurin and its metabolites can act as CYP3A4 substrates, inhibitors, and inducers and also affect their own metabolic clearance (CL) (Fahmi et al., 2009; Fenneteau et al., 2010; Reitman et al., 2011; Rowland Yeo et al., 2011; European Medicines Agency, 2012; Food and Drug Administration, 2012; Garg et al., 2012; Prueksaritanont et al., 2013) or that of other drugs.

In the initial phase of development, DDI studies were conducted in healthy volunteers to address the clinical relevance of CYP3A4-related DDIs, with midostaurin as either a victim of a ketoconazole or rifampicin interaction or a perpetrator of midazolam (Dutreix et al., 2013, 2014). However, these early clinical studies were conducted mostly using relatively short dosing periods. The terminal half-lives of midostaurin, CGP62221, and CGP52421 in plasma are 19.6, 32.2, and 482 hours, respectively. Due to the complex DDI mechanisms of midostaurin and its metabolites, it is important to evaluate potential DDIs under steadystate conditions to support clinical recommendations and potential product label language. Because such DDI studies are not feasible in healthy subjects, we aimed to use a multipronged approach to investigate the net effect of steady-state midostaurin on CYP3A4 activity. To achieve this goal, we did the following: 1) built a physiologically based pharmacokinetic (PBPK) model to describe the pharmacokinetics (PK) of midostaurin and its two active metabolites using a top-down approach leveraging prior clinical PK data in both healthy subjects and patients; 2) verified the performance of the model in predicting clinical PK profiles of midostaurin and its metabolites, particularly in simulating clinically observed DDIs under single-dose conditions; and 3) used the model to predict CYP3A4-related DDIs with midostaurin at steady state. Furthermore, the utility of the endogenous plasma biomarker $4 \beta$ hydroxycholesterol $(4 \beta \mathrm{HC})$ as a tool for assessing CYP3A4 activity was explored to address the uncertainty in evaluating the net effect of CYP3A4 induction or inhibition of new molecular entities that have mixed inhibition or induction DDI mechanisms in vitro. The final model was also used to predict DDI potential with other CYP3A4 substrates, inhibitors, and inducers; the model limitations are discussed. The prediction results from our case example provide a basis for optimal clinical study recommendations and potential label language.

\section{Materials and Methods}

PBPK modeling was accomplished following these general steps: 1) the model was initially developed using physiochemical data; absorption, distribution, metabolism, and excretion (ADME) data; and in vitro DDI study data and optimized to fit the clinical PK data of the parent and its two metabolites; 2) the model was verified by comparing simulated data with data from clinical DDI studies; and 3) the model was applied to predict potential DDI effects of CYP3A4 inhibitors or inducers on midostaurin and its metabolites as well as effects on midazolam under steady-state conditions. Finally, the results from plasma $4 \beta \mathrm{HC}$ levels (fold change relative to baseline) were used to confirm the net effect of time-dependent inhibition/induction of CYP3A4 by midostaurin and its metabolites.

\section{PBPK Model Development in Healthy Subjects}

A PBPK model was built using Simcyp Simulator, version 15, release 1 (Certara, LP, Princeton, NJ) for midostaurin and its two metabolites, CGP52421 and CGP62221, using in vitro ADME and in vivo PK data. The key input parameters are summarized in Table 1, and described here.

Physiochemical Properties and Plasma Binding. The molecular weights of midostaurin, CGP52421, and CGP62221 are 570.6, 586.6, and 556.6 g/mol, respectively, and the water partition coefficient (logP octanol:water) ratios used were 5.5, 4.8, and 4.7 (calculated $\log \mathrm{P}$ values), respectively. The compound type was entered as a monoprotic base, with a $K_{\mathrm{a}}$ value of 11.2 for midostaurin and CGP62221 and a $K_{\mathrm{a}}$ value of 10.8 for CGP52421 (predicted using ADMET Predictor version 6.5; Simulations Plus, Lancaster, CA). The blood-to-plasma ratios for midostaurin, CGP62221, and CGP52421 were entered as 0.55 based on the internal experimental values.

The fractions bound to plasma for all three components were very high ( $>99 \%$ ). For these very highly bound compounds, an equilibrium gel filtration method was used (Weiss and Gatlik, 2014; He et al., 2017). Midostaurin was mainly bound to human $\alpha 1$-acid glycoprotein (AGP) according to an internal study. Therefore, AGP was selected as a plasma-binding component in the model.

Absorption. A first-order model for midostaurin absorption from the gut lumen was chosen. Several key input parameters were applied. First, the fraction of dose absorbed $\left(\mathrm{F}_{\mathrm{a}}\right)$ was entered as 0.85 , primarily to optimize the $C_{\max }$, based on the observed data from a single oral 50 -mg dose of midostaurin in a prior clinical study. This $\mathrm{F}_{\mathrm{a}}$ value was consistent with the moderate to high absorption observed in preclinical species and humans (He et al., 2017). The absorption rate constant and lag time were user defined as $1.51 / \mathrm{h}$ and 0.3 hours, respectively, to optimize $C_{\max }$ and the time at which $C_{\max }$ is reached that were observed in several clinical trials (after a single dose). Second, the fraction of unbound drug in the gut $\left(\mathrm{fu}_{\mathrm{gut}}\right)$ was predicted to be 0.3 , and, accordingly, by Simcyp, the output fraction of the dose that escapes presystemic intestinal first-pass elimination $\left(F_{g}\right)$ value was 0.15 , a value derived from the Simcyp-predicted fu $u_{\text {gut }}$ value. This predicted human $F_{g}$ value was consistent with the observed rat $F_{g}$ value based on calculations from data obtained in a rat in vivo study (data not shown). Finally, the nominal flow through the gut value captures the fact that a higher permeability past the enzyme will decrease first-pass exposure to the enzyme, as will a greater blood flow carrying the drug away from the enterocytes. The value was predicted to be $5.23 \mathrm{l} / \mathrm{h}$ with Simcyp, using the apparent permeability data from an internal continuous heterogeneous human epithelial colorectal adenocarcinoma cell line (Caco-2) study.

Distribution. The minimal PBPK model in Simcyp was used with a single adjusting compartment for all three components. The volume of distribution at steady state $\left(\mathrm{V}_{\mathrm{ss}}\right)$ was estimated to be $1 \mathrm{l} / \mathrm{kg}$, with parameters for a intercompartmental CL (Q) of $3 \mathrm{l} / \mathrm{h}$ and a volume of distribution for the single adjustable compartment $\left(\mathrm{V}_{\mathrm{sac}}\right)$ of $0.821 / \mathrm{kg}$. The estimated midostaurin oral $\mathrm{V}_{\mathrm{ss}}$ value was close to the observed geometric mean (GM) or median apparent volume of distribution values, which ranged from 1.0 to $1.31 / \mathrm{kg}$. For CGP52421, the $\mathrm{V}_{\mathrm{ss}}$ value was estimated to be $1.81 / \mathrm{kg}$, with a $\mathrm{Q}$ of $10 \mathrm{l} / \mathrm{h}$ and a $\mathrm{V}_{\mathrm{sac}}$ of $1.31 / \mathrm{kg}$. For CGP62221, the $V_{\text {ss }}$ value was estimated to be $1.31 / \mathrm{kg}$, with a $\mathrm{Q}$ of $2 \mathrm{l} / \mathrm{h}$ and a $\mathrm{V}_{\text {sac }}$ of $1.1 \mathrm{l} / \mathrm{kg}$. All values were estimated based on optimization to best fit to PK data from clinical trials (Supplemental Table 9).

Elimination. The retrograde model was used to calculate in vitro intrinsic CL $\left(\mathrm{CL}_{\text {int }}\right)$ values of the relevant metabolizing enzymes from intravenous or apparent oral CL (CL/F). In brief, the CL/F of $2.4 \mathrm{l} / \mathrm{h}$ was estimated to optimize the plasma concentration-time profiles of midostaurin observed in the clinical trials used for model development. This estimated oral CL value was consistent with the observed median or GM CL/F values, which ranged from 2.1 to $3.8 \mathrm{l} / \mathrm{h}$. The fraction metabolized by CYP3A4 was set to a value of 1 for midostaurin based on human in vitro findings and the human ADME study. As such, the CYP3A $4 \mathrm{CL}_{\text {int }}$ value was calculated to be $\sim 25.2 \mu \mathrm{l} / \mathrm{min} / \mathrm{mg}$ per picomole CYP3A4 by the retrograde model for enzyme kinetics in Simcyp. In a second step, the CYP3A4 $\mathrm{CL}_{\text {int }}$ was divided between the involved elimination pathways (i.e., CGP52421, CGP62221, and other CYP3A4-mediated pathways). The fraction of CYP3A4 for the metabolism (formation of CGP52421 and CGP62221)/elimination of midostaurin was estimated. The estimations are based mainly on an enzyme 
TABLE 1

Input parameters for midostaurin, CGP52421, and CGP62221

\begin{tabular}{|c|c|c|c|c|c|c|}
\hline \multirow{2}{*}{ Parameter } & \multicolumn{2}{|c|}{ Midostaurin } & \multicolumn{2}{|c|}{ CGP52421 } & \multicolumn{2}{|r|}{ CGP62221 } \\
\hline & Value & Reference & Value & Reference & Value & Reference \\
\hline mol. wt. (g/mol) & 570.6 & & 586.6 & & 556.6 & \\
\hline $\log$ Po:w & 5.49 & Internal database & 4.76 & Internal database & 4.68 & Internal database \\
\hline $\mathrm{pKa}$ & 11.2 & Predicted $^{a}$ & 10.8 & Predicted $^{a}$ & 11.2 & Predicted $^{a}$ \\
\hline Compound type & Monoprotic base & & & & & \\
\hline $\mathrm{f}_{\text {up }}$ & 0.00015 & Internally measured & 0.00021 & Internally measured & 0.00038 & Internally measured \\
\hline $\mathrm{B} / \mathrm{P}$ & 0.55 & & 0.55 & Assumed same as & 0.55 & Assumed same as \\
\hline Plasma-binding component & AGP & & AGP & parent & AGP & parent \\
\hline \multicolumn{7}{|l|}{ First-order absorption } \\
\hline $\mathrm{F}_{\mathrm{a}}$ & $0.85(0.65$, advSM $)$ & User defined & & & & \\
\hline $\mathrm{k}_{\mathrm{a}}\left(\mathrm{h}^{-1}\right)$ & $1.5(0.683, \mathrm{advSM})$ & (optimized) & & & & \\
\hline Lag time (h) & 0.3 & & & & & \\
\hline $\mathrm{Q}_{\text {gut }}(1 / \mathrm{h})$ & 5.23 & Simcyp predicted & & & & \\
\hline $\mathrm{fu}_{\text {gut }}$ & 0.3 & & & & & \\
\hline Peff, man $\left(10^{-4} \mathrm{~cm} / \mathrm{s}\right)$ & 0.835 & & & & & \\
\hline Caco-2 $\left(10^{-6} \mathrm{~cm} / \mathrm{s}\right)$ & 1.4 & Internally measured & & & & \\
\hline $\begin{array}{l}\text { Caco- } 2 \text { reference } \\
\quad\left(10^{-6} \mathrm{~cm} / \mathrm{s}\right)\end{array}$ & 17 & & & & & \\
\hline \multicolumn{7}{|l|}{$\begin{array}{l}\text { Minimal with single adjusting } \\
\text { compartmental distribution }\end{array}$} \\
\hline $\mathrm{Q}(1 / \mathrm{h})$ & $\begin{array}{c}3(2.889 \\
\text { AML/advSM) }\end{array}$ & $\begin{array}{c}\text { Estimated from } \\
\text { clinical } \\
\text { PK data (a single- }\end{array}$ & 10 & $\begin{array}{l}\text { Estimated from clinical } \\
\text { PK data (a single-dose } \\
\text { trial) }\end{array}$ & 2 & $\begin{array}{c}\text { Estimated from clinical } \\
\text { PK data (a single-dose } \\
\text { trial) }\end{array}$ \\
\hline Volume $\left(\mathrm{V}_{\mathrm{sac}}[\mathrm{l} / \mathrm{h}]\right)$ & $\begin{array}{c}0.82(0.623 \\
\text { AML/advSM })\end{array}$ & dose trial) & 1.8 & & 1.1 & \\
\hline $\mathrm{V}_{\mathrm{ss}}(\mathrm{l} / \mathrm{h})$ & $\begin{array}{c}1(0.742 \\
\text { AML/advSM })\end{array}$ & & 1.3 & & 1.3 & \\
\hline \multicolumn{7}{|l|}{ Elimination } \\
\hline Hepatic CL by CYP3A4 (\%) & 100 & $\begin{array}{l}\text { Estimated from } \\
\text { human } \\
\text { ADME study }\end{array}$ & 90 & $\begin{array}{l}\text { Estimated from human } \\
\text { ADME study }\end{array}$ & 90 & $\begin{array}{c}\text { Estimated from human } \\
\text { ADME study }\end{array}$ \\
\hline $\begin{array}{l}\mathrm{CL}_{\mathrm{int}}, \mathrm{CYP} 3 \mathrm{~A} 4 \text { formation of } \\
\text { CGP52421 }(\mu \mathrm{l} / \mathrm{min} \text { per } \\
\text { picomole CYP3A4) }\end{array}$ & $\begin{array}{c}9.3(3.9 \\
\text { AML/advSM) }\end{array}$ & See Elimination & & & & \\
\hline $\begin{array}{l}\mathrm{CL}_{\text {int }}, \text { CYP3A4 formation of } \\
\text { CGP62221 }(\mu \mathrm{l} / \mathrm{min} \text { per } \\
\text { picomole CYP3A4) }\end{array}$ & $\begin{array}{c}9.3(3.9 \\
\text { AML/advSM) }\end{array}$ & & & & & \\
\hline $\begin{array}{c}\mathrm{CL}_{\text {int }}, \text { CYP3A4 formation of } \\
\text { other metabolites }(\mu 1 / \mathrm{min} \\
\text { per picomole CYP3A4) }\end{array}$ & $\begin{array}{c}6.6(2.8 \\
\text { AML/advSM) }\end{array}$ & & $\begin{array}{c}3.18 \text { (0.557, AML } \\
\text { patients) }\end{array}$ & & 1.19 & \\
\hline $\begin{array}{l}\text { Additional HLM CL }(\mu 1 / \mathrm{min} \\
\text { per milligram protein })\end{array}$ & & & $\begin{array}{l}48.4(6.48, \text { AML } \\
\text { patients })\end{array}$ & & 18.1 & \\
\hline $\begin{array}{l}\text { Active uptake into } \\
\text { hepatocytes }\end{array}$ & 1 & Default & & & & \\
\hline $\mathrm{CL}_{\mathrm{R}}$ & 0 & See Elimination & & & & \\
\hline \multicolumn{7}{|l|}{ CYP3A4-related interaction } \\
\hline $\begin{array}{l}\text { Reversible inhibition } \\
\text { CYP3A4 } K_{\text {iu }}(\mu \mathrm{M})\end{array}$ & 0.25 & $\begin{array}{l}\text { Internally measured } \\
\text { (Supplemental } \\
\text { Table 2) }\end{array}$ & 0.44 & $\begin{array}{c}\text { Internally measured } \\
\text { (Supplemental Table 2) }\end{array}$ & 0.25 & $\begin{array}{c}\text { Internally measured } \\
\text { (Supplemental Table 2) }\end{array}$ \\
\hline $\begin{array}{l}\text { TDI } \mathrm{K}_{\mathrm{I}} \text {, total }(\mu \mathrm{M}) k_{\text {inact }} \\
\quad(1 / \mathrm{h})\end{array}$ & 1.022 .8 & $\begin{array}{c}\text { Internally measured } \\
\text { (Supplemental } \\
\text { Table 3) }\end{array}$ & 1.973 .0 & $\begin{array}{c}\text { Internally measured } \\
\text { (Supplemental Table 3) }\end{array}$ & 2.014 .62 & $\begin{array}{c}\text { Internally measured } \\
\text { (Supplemental Table 3) }\end{array}$ \\
\hline $\begin{array}{l}\text { Induction of CYP3A4 } \text { Ind }_{\max } \\
\quad \text { (fold) } \operatorname{IndC}_{50}(\mu \mathrm{M})\end{array}$ & 9.140 .0026 & $\begin{array}{l}\text { Internally measured } \\
\text { (Supplemental } \\
\text { Table 4) and } \\
\text { optimized }\end{array}$ & 10.80 .0053 & $\begin{array}{c}\text { Internally measured } \\
\text { (Supplemental Table 4) } \\
\text { and optimized }\end{array}$ & $\begin{array}{c}11.97 \\
0.0027\end{array}$ & $\begin{array}{c}\text { Internally measured } \\
\text { (Supplemental Table 4) } \\
\text { and optimized }\end{array}$ \\
\hline
\end{tabular}

$\mathrm{B} / \mathrm{P}$, blood-to-plasma ratio; $\mathrm{CL}_{\mathrm{R}}$, renal $\mathrm{CL} ; \mathrm{fu}_{\mathrm{p}}$, fraction of unbound drug in plasma; $\mathrm{Ind}_{50}$, half-maximum induction rate; IndC $\mathrm{C}_{50}$, concentration of inducer at half-maximal induction; Ind max $_{2}$

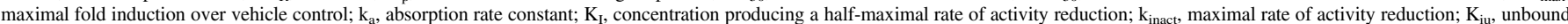
inhibition constant; $\operatorname{logPo}$ :w, water partition coefficient; Peff, man, effective permeability in man; $\mathrm{Q}_{\text {gut }}$, nominal flow through the gut.

${ }^{a}$ Determined using ADMET Predictor version 6.5 (Simulations Plus).

phenotyping study using human liver microsomes (HLMs) and cytochrome P450-selective chemical inhibitors; the estimations showed that CYP3A4 contributed to most of the hepatic oxidative microsomal metabolism of midostaurin. Furthermore, CGP52421 and CGP62221 are also metabolized mainly by CYP3A4. The human ADME study (He et al., 2017) showed that midostaurin undergoes extensive metabolism and is predominantly excreted through feces, mostly as metabolites. The fractions of CYP3A4 for the metabolism/elimination of midostaurin in human fecal excreta were estimated to be $37 \%, 37 \%$, and $26 \%$ for CGP52421, CGP62221, and other minor metabolites, respectively. Consequently, the values of $\mathrm{CL}_{\text {int }}$ in microliters per minute per picomole CYP3A4 were assigned to the following CYP3A4 pathways (in $\mu 1 / \mathrm{min}$ per picomole CYP3A4): CGP52421, 9.3; CGP62221, 9.3; other CYP3A4, 6.6.

For the oral $\mathrm{CL} / \mathrm{F}$, the values were estimated to be 0.4 and $0.27 \mathrm{l} / \mathrm{h}$ for CGP52421 and CGP62221, respectively, based on optimization to best fit to the plasma concentration-time profiles of these metabolites from clinical trials. Furthermore, it was assumed that approximately 90\% of CGP52421 and CGP62221 CL was mediated by CYP3A4, because they were detected at low 
levels in human excreta. The CYP3A4 $\mathrm{CL}_{\text {int }}$ values derived from the $\mathrm{CL} / \mathrm{F}$ were predicted by the retrograde model to be $3.18 \mu \mathrm{l} / \mathrm{min}$ per picomole CYP3A4 and $1.19 \mu \mathrm{l} / \mathrm{min}$ per picomole CYP3A4 for CGP52421 and CGP62221, respectively.

Data from the human ADME study indicated that midostaurin in urine was not detected, as shown in a high-performance liquid chromatography profile of radioactive components in pooled urine (0-72 hours). Therefore, the renal CL was assumed to be negligible and set to $0 \mathrm{l} / \mathrm{h}$.

Interaction. The potential of midostaurin, CGP52421, and CGP62221 to inhibit human CYP3A4/5 enzyme activity and act as CYP3A4/5 TDIs was assessed using pooled HLMs (Supplemental Material). The potential for midostaurin, CGP52421, and CGP62221 to act as inducers of CYP3A4/5 enzymes was also evaluated in primary human hepatocytes of three individual donors using both mRNA quantification (real-time polymerase chain reaction) and CYP3A4/5 activity measurements (Supplemental Material). All of the in vitro enzyme activity was determined using liquid chromatography-tandem mass spectrometry of selective CYP3A4/5 probe substrate metabolism (Supplemental Material). The input parameters used for the induction of CYP3A4, TDI, and reversible inhibition of CYP3A4/5 are summarized in Table 1.

Model Assumptions. Several assumptions were made for the projection of human PK parameters. First, human $\mathrm{F}_{\mathrm{a}}$ was set to 0.85 (see Absorption). Next, the fractions of total metabolism catalyzed by CYP3A4 in humans were estimated to be fractions of total CGP52421 metabolism catalyzed by CYP3A4 of $\sim 0.37$, fractions of total CGP62221 metabolism catalyzed by CYP3A 4 of $\sim 0.37$, and fractions of total other metabolite metabolism catalyzed by CYP3A 4 of $\sim 0.26$, with the assumptions that metabolite epimer structures were similar and that sequentially formed metabolites were equally contributed by primary and secondary metabolism. The CYP3A4/5 TDI total concentration producing a half-maximal rate of activity reduction (total $\mathrm{K}_{\mathrm{I}}$ ) was used. The CYP3A4 mRNA induction $\mathrm{EC}_{50}$ values of midostaurin, CGP52421, and CGP62221 were entered and optimized in the models (i.e., 20-fold more potent than the experimental value). These modifications (i.e., lower $\mathrm{EC}_{50}$ and fixed maximal induction) were judged to be appropriate based on the very high plasma protein binding of all three components observed ( $>99 \%)$; lower intracellular free concentrations in hepatocytes would be expected, which could reflect the amount of drug available for binding to the pregnane $\mathrm{X}$ receptor. The model was developed and verified using data from clinical studies in healthy subjects (further details follow). The diseaseand/or age-related physiologic changes affecting drug ADME properties, including enzyme activity and function, were not considered. Finally, the transporter-related drug interaction property was not included in the model.

Population. The simulations were performed using a simulated healthy volunteer population (Pop) built in the Simcyp simulator, with individuals who were 20-55 years of age; the proportion of female subjects was set to $50 \%$. The Pop size was 100 , with 10 trials of 10 subjects per trial.

Simulation Trials. The simulated trials were run in a fasted state. The simulated trials for plasma PK of midostaurin and its two metabolites after single and multiple twice-daily doses are presented as follows. First, observed and predicted PK parameters and plasma concentration-time profiles of midostaurin, CGP52421, and CGP62221 after a single dose of midostaurin with a final market image (FMI) formulation of $50 \mathrm{mg}$ in the simulated subjects were compared with those in healthy volunteers in clinical studies. Control arms included food effect, relative bioavailability, DDIs with ketoconazole, and DDIs with rifampicin. Second, observed and predicted PK parameters and plasma concentration-time profiles of midostaurin, CGP52421, and CGP62221 after midostaurin (FMI) $75 \mathrm{mg}$ twice daily on days 1 and 2 and $75 \mathrm{mg}$ daily on day 3 in the simulated subjects were compared with those in healthy volunteers in a cardiac intervals investigation. Third, observed and predicted PK parameters and plasma concentration-time profiles of midostaurin, CGP52421, and CGP62221 after midostaurin (FMI) $50 \mathrm{mg}$ twice daily on days 1-6 and a single dose on day 7 in the simulated subjects were compared with those in healthy subjects with normal hepatic function in a PK study in subjects with impaired hepatic function.

\section{PBPK Model Performance}

The performance of the PBPK model was verified by comparing the simulated data with clinically observed DDIs. Input parameters for the PBPK model are in Supplemental Tables 10-15. The ketoconazole, rifampicin, and midazolam models available in the Simcyp compound library were used in the simulations. The simulated trials for plasma PK of midostaurin and its two metabolites in the presence of CYP3A4/5 inhibitors, a CYP3A4 inducer, or sensitive CYP3A4 substrates are shown in Table 2.

\section{PBPK Model Development in Patients with AML and AdvSM}

A PBPK model was also built to simulate the PK of midostaurin and its metabolites in patients with AML and advSM using a top-down approach. The model was mainly adopted from the previous Simcyp model in healthy subjects but with modifications. The assumption of these two patient models was that the protein binding fraction metabolized by CYP3A4 and in vitro DDI parameters of midostaurin and its metabolites were the same in patients and healthy subjects. The parameters were updated based on the parameter estimated in the Pop PK of midostaurin in patients with AML and advSM. These values were entered as described in the model for healthy subjects, with the exception of the following changes (Table 1).

For patients with AML, parameters of distribution and elimination for midostaurin and parameters of elimination for CGP52421 were updated in the model for healthy subjects. $\mathrm{V}_{\mathrm{ss}}$ values of midostaurin were changed from 1 to $0.742 \mathrm{l} / \mathrm{kg}$, with changes in parameters for $\mathrm{Q}(3-2.889 \mathrm{l} / \mathrm{h})$ and $\mathrm{V}_{\text {sac }}(0.82-0.623$ $1 / \mathrm{kg}$ ). $\mathrm{CL}_{\text {int }}$ of midostaurin was changed from $\sim 25.2$ to $10.6 \mu 1 / \mathrm{min}$ per milligram per picomole isoform. Accordingly, the midostaurin value of $\mathrm{CL}_{\text {int }}$ (in microliters per minute per picomole CYP3A4) was assigned to the following CYP3A4 pathways: CGP52421 $(37 \%)=3.9$; CGP62221 $(37 \%)=3.9$; other $(26 \%)=2.8$. For CGP52421, CL/F and CL $\mathrm{L}_{\text {int }}$ were changed from 0.4 to $0.07 \mathrm{l} / \mathrm{h}$ and from 3.18 to $0.557 \mu \mathrm{l} / \mathrm{min}$ per milligram per picomole CYP3A4, respectively, with additional HLM CL of $6.48 \mu \mathrm{l} / \mathrm{min}$ per milligram protein. Comparison of PBPK-simulated and Pop PK-simulated data can be found in Supplemental Table 5, indicating that PBPK-simulated area under the curve (AUC) and $C_{\max }$ values were within $\leq 2$-fold of the values in the Pop PK data analysis.

For patients with advSM, parameters of absorption, distribution, and elimination for midostaurin were updated in the model for healthy subjects, so that the same $\mathrm{V}_{\mathrm{ss}}$ and $\mathrm{CL}_{\text {int }}$ values of midostaurin used in the model for patients with AML were used in the model for patients with advSM. In addition, the midostaurin $\mathrm{F}_{\mathrm{a}}$ value was changed from 0.85 to 0.65 , and the absorption rate constant was changed from 1.5 to $0.683 \mathrm{l} / \mathrm{h}$. These values were updated based on optimization to best fit to Pop PK data in patients with advSM. Comparison of PBPK-simulated and Pop PK-simulated data can be found in Supplemental Table 6, indicating that PBPK-simulated AUC and $C_{\max }$ values were within $\leq 2$ fold of the values in the Pop PK data analysis.

\section{PBPK Model Application}

After model verifications using data from clinical PK studies as well as clinical DDIs with ketoconazole, rifampicin, and midazolam in healthy subjects, the model was used to simulate hypothetical DDI scenarios at steady-state levels in healthy subjects and in patients with AML and advSM. These scenarios included 1) predicting the effect of moderate and strong CYP3A4 inhibitors and inducers on the exposure of midostaurin and its metabolites and 2) predicting the effect of midostaurin on the exposure of midazolam.

Simulation of the Effects of Moderate and Strong CYP3A4 Inhibitors and Inducers. The potential effects of CYP3A4 inhibitors fluconazole (moderate), itraconazole (strong), and ketoconazole (strong) and those of inducers efavirenz (moderate) and rifampicin (strong) on the PK of midostaurin and its metabolites were simulated. The Simcyp default PBPK models for efavirenz, fluconazole, and itraconazole (fed capsule) with $\mathrm{OH}$-itraconazole, ketoconazole, and rifampicin were used in these simulations. Next, midostaurin $50 \mathrm{mg}$ twice daily was administered for 21 days; efavirenz $600 \mathrm{mg}$ daily, fluconazole $200 \mathrm{mg}$ daily, itraconazole $100 \mathrm{mg}$ twice daily, ketoconazole $400 \mathrm{mg}$ daily, or rifampicin $600 \mathrm{mg}$ daily was coadministered with midostaurin for 7 days, starting on day 22. The effects of inhibitors and inducers on the PK of midostaurin were assessed after the last midostaurin dose on day 28.

Simulation of the Effects of Midostaurin and Its Metabolites on Midazolam. Due to a technical limitation in the current version of Simcyp, the model does not have the ability to enter midostaurin with two metabolites as perpetrators. Therefore, an alternative approach was used in which the simulations were performed using the perpetrator as the substrate of the model and the victim as the inhibitor of the model. Briefly, two simulations were conducted with midostaurin and its two metabolites in the substrate position and midazolam in the inhibitor position. In the first simulation, the DDI properties of midostaurin and its 
TABLE 2

Summary of trial simulation design

\begin{tabular}{|c|c|c|c|c|}
\hline & Simulated Pop & Observed Pop & Dosing Regimen & PK Measurement of Substrate \\
\hline $\begin{array}{l}\text { Model performance of midostaurin PK and } \\
\text { ketoconazole DDIs }\end{array}$ & $\begin{array}{l}\text { Healthy } \\
\text { volunteer }\end{array}$ & $\begin{array}{l}\text { Healthy } \\
\text { volunteer }\end{array}$ & $\begin{array}{l}\text { Ketoconazole } 400 \mathrm{mg} \text { daily on days } 1-10+ \\
\text { midostaurin (FMI) } 50 \mathrm{mg} \text { on day } 6\end{array}$ & $0-120 \mathrm{~h}, 0$-inf \\
\hline $\begin{array}{l}\text { Model performance of midostaurin PK and } \\
\text { rifampicin DDIs }\end{array}$ & $\begin{array}{l}\text { Healthy } \\
\text { volunteer }\end{array}$ & $\begin{array}{l}\text { Healthy } \\
\text { volunteer }\end{array}$ & $\begin{array}{c}\text { Rifampicin } 600 \mathrm{mg} \text { daily on days } 1-14+ \\
\text { midostaurin (FMI) } 50 \mathrm{mg} \text { on day } 9\end{array}$ & $0-144 \mathrm{~h}, 0$-inf \\
\hline $\begin{array}{l}\text { Model performance of midazolam PK and } \\
\text { midostaurin-midazolam DDIs }\end{array}$ & $\begin{array}{l}\text { Healthy } \\
\text { volunteer }\end{array}$ & $\begin{array}{l}\text { Healthy } \\
\text { volunteer }\end{array}$ & $\begin{array}{c}\text { Midazolam } 4 \mathrm{mg} \text { daily on days } 1 \text { and } 6+ \\
\text { midostaurin } 100-\mathrm{mg} \text { single dose on day } 1,50 \mathrm{mg} \\
\text { twice daily on days } 2-4\end{array}$ & $\begin{array}{c}\text { Day 1: } 0-10 \mathrm{~h}, 0-\text { inf Day 6: } \\
0-10 \mathrm{~h}\end{array}$ \\
\hline
\end{tabular}

metabolite CYP3A were turned off, representing the control PK of midazolam (in the absence of interaction). The second simulation was performed in the presence of midostaurin by including all the DDI properties, representing the interaction between midazolam as a perpetrator on midostaurin and its metabolites as victims. The exposure parameters (e.g., AUC and $C_{\mathrm{max}}$ ) of midazolam from the first simulation were compared with those of the second simulation to determine the effect of midostaurin and its metabolites on midazolam. The dose regimen was midazolam $4 \mathrm{mg}$ on day 28 , with midostaurin $50 \mathrm{mg}$ twice daily on days 1-28.

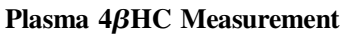

Study Design. Healthy adult volunteers $18-55$ years of age were randomized to receive either rifampicin $600 \mathrm{mg}$ (positive control) or placebo (negative control) from day 1 to 14 . All individuals received midostaurin $50 \mathrm{mg}$ on day 9. This unique, single administration was deemed not to interfere with the rifampicinplacebo effect. The positive control $\operatorname{arm}(n=20)$ and negative control arm $(n=20)$ served as references for the progression of $4 \beta \mathrm{HC}$ levels. In a separate study, data from patients with advSM enrolled in an open-label, phase 2 study who received midostaurin $100 \mathrm{mg}$ twice daily for 28 days $(n=10)$ were used to determine the $4 \beta \mathrm{HC}$ concentration profile. The study was conducted in accordance with the Declaration of Helsinki and approved by all relevant institutional review boards and ethics committees. The study design is summarized in Table 3 .

Sample Collection and Analysis. To evaluate the plasma concentration of $4 \beta \mathrm{HC}$, peripheral blood samples were collected on days 1 (baseline), 9 (before receiving midostaurin), 11 , and 15 in the positive and negative control arms (healthy participants in a clinical DDI study with rifampicin) and on days $1,3,8$, 15,22 , and 28 of cycle 1 in the patient study. The plasma concentration of $4 \beta \mathrm{HC}$ was measured as described (Diczfalusy et al., 2011), using validated liquid chromatography-tandem mass spectrometry with a lower limit of quantification of $3 \mathrm{ng} / \mathrm{ml}$.

Statistical Analyses. Statistical analyses were descriptive only; no formal statistical tests were performed. Only subjects with an available full $4 \beta \mathrm{HC}$ profile were included in the analysis. For each subject, values at each time point and the percentage change from baseline were considered and median values were computed (data not shown); the mean and GM of the individual value from baseline were also calculated. Results were plotted to visually represent the data and support the interpretations.

\section{Results}

Simulated and Observed PK after Single and Multiple Doses of Midostaurin in Healthy Subjects

A Simcyp model was established to predict the PK of midostaurin, CGP52421, and CGP62221 after single (50 mg) and multiple (50 or $75 \mathrm{mg}$ ) oral doses in healthy subjects. Simulated PK profiles were compared with data from several clinical trials in which single-agent PK data were available. Overall, the PK of midostaurin, CGP52421, and CGP62221 were predicted reasonably well. The simulated mean plasma concentration-time profiles with observed data overlaid are shown in Fig. 1. The representative tabulated simulated and actual PK parameters for midostaurin, CGP52421, and CGP62221 after a single dose of $50 \mathrm{mg}$ and $50 \mathrm{mg}$ twice daily of midostaurin can be found in Supplemental Tables 7 and 8.

\section{Simulated and Observed DDIs with CYP3A4 Inhibitor Ketoconazole and Inducer Rifampicin in Healthy Subjects}

The clinical DDI trial of midostaurin $50 \mathrm{mg}$ with ketoconazole $400 \mathrm{mg}$ daily or rifampicin $600 \mathrm{mg}$ daily was simulated according to the clinical trial design in healthy subjects. Simulated profiles for the interaction of midostaurin and ketoconazole or midostaurin and rifampicin were then compared with observed data, as shown in Fig. 2.

The predicted and observed midostaurin AUC GM ratios (GMRs) were $5.8\left(\mathrm{AUC}_{\mathrm{inf}}, 6.3\right)$ and $6.1\left(\mathrm{AUC}_{\mathrm{inf}}, 10.4\right)$, respectively, and the predicted and observed $C_{\max }$ GMRs were 2.1 and 1.8, respectively, when midostaurin was coadministered with ketoconazole. For

TABLE 3

4 $\beta$ HC STUDY design (CPKC412A2110; registered as EudraCT no. 2009-009895-11)

\begin{tabular}{|c|c|c|c|c|c|c|c|c|c|c|c|c|c|c|c|c|c|}
\hline \multirow{2}{*}{ Pop } & \multirow{2}{*}{ Study Arm } & \multirow{2}{*}{ Treatment } & \multirow{2}{*}{$\begin{array}{c}\text { Screening } \\
(\text { Days }-14 \text { to }-1)\end{array}$} & \multicolumn{14}{|c|}{ Study Day } \\
\hline & & & & Baseline (1) & 2 & 3 & $4-7$ & 8 & 9 & 10 & 11 & $12-14$ & 15 & $16-21$ & 22 & $23-27$ & 28 \\
\hline \multirow{4}{*}{ Healthy volunteers } & Negative control & Placebo daily & & $a$ & $a$ & $a$ & $a$ & $a$ & $a$ & $a$ & $a$ & $a$ & & & & & \\
\hline & $(n=20)$ & Midostaurin $50 \mathrm{mg}$ twice daily & & & & & & & $b$ & & & & & & & & \\
\hline & Positive control & Rifampicin $600 \mathrm{mg}$ daily & & $c$ & $c$ & $c$ & $c$ & $c$ & $c$ & $c$ & $c$ & $c$ & & & & & \\
\hline & $\begin{array}{c}(n=20) \\
\text { PK }\end{array}$ & Midostaurin $50 \mathrm{mg}$ twice daily & & d & & & & & $\begin{array}{l}b \\
d\end{array}$ & & $d$ & & $d$ & & & & \\
\hline \multirow[t]{2}{*}{ Patients with advSM } & $\begin{array}{l}\text { Midostaurin arm } \\
\qquad(n=10)\end{array}$ & Midostaurin $100 \mathrm{mg}$ twice daily & & $b$ & $b$ & $b$ & $b$ & $b$ & $b$ & $b$ & $b$ & $b$ & $b$ & $b$ & $b$ & $b$ & $b$ \\
\hline & PK assessment & $4 \beta \mathrm{HC}$ & & $\mathrm{e}$ & & $e$ & & $e$ & & & & & $e$ & & $e$ & & $e$ \\
\hline
\end{tabular}

${ }^{a}$ Receipt of placebo.

${ }^{b}$ Treatment with midostaurin.

${ }^{c}$ Treatment with rifampicin (a CYP3A4 inducer)

Blood samples for the assessment of $4 \beta \mathrm{HC}$ in serum were taken as follows:

${ }^{d}$ Blood samples for the assessment of $4 \beta \mathrm{HC}$ in serum for healthy volunteers: days 1, 9 (before midostaurin treatment), 11, and 15;

${ }^{e}$ Blood samples for the assessment of $4 \beta \mathrm{HC}$ in serum for patients with advSM: days $1,3,8,15,22$, and 28 . 
Gu et al.
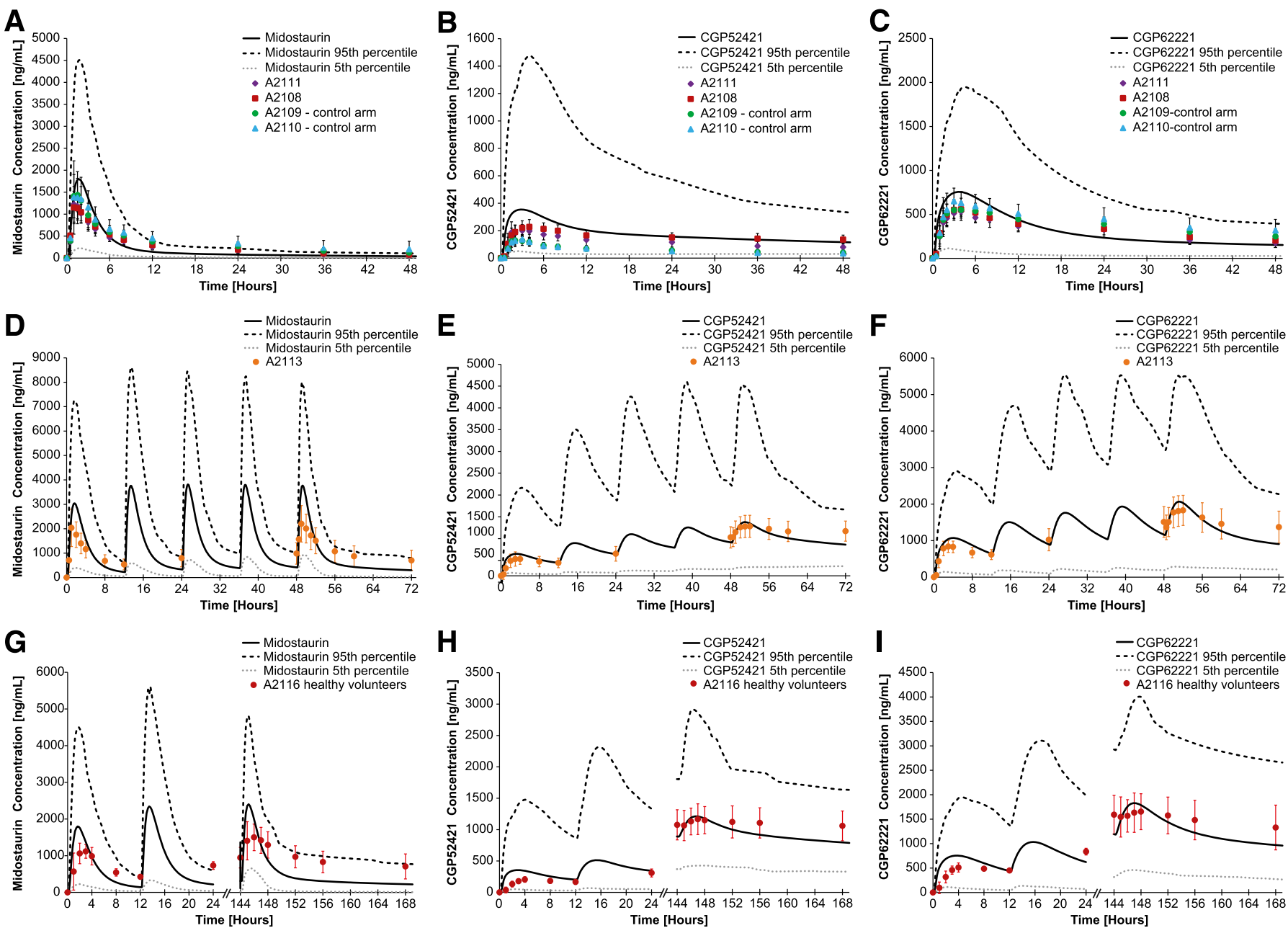

Fig. 1. The black lines represent the simulated mean plasma concentration-time profiles of midostaurin (A, D, and G), CGP52421 (B, E, and H), and CGP62221 (C, F, and I). The dashed lines represent the simulated lower 5th and upper 95th percentiles. The symbols and error bars represent the observed mean plasma concentration-time data and S.D. from two clinical trials (A2111 and A2108) and two control trials (A2109 and A2110) for (A, B, and C). All four trials were open-label, randomized, parallel-group studies in healthy volunteers. (A, B, and C) show day 1 after treatment with midostaurin $50 \mathrm{mg}$; (D, E, and F) show days 1-3 after treatment with midostaurin $75 \mathrm{mg}$ twice daily for 3 days; and (G, H, and I) show days 1 and 7 after treatment with midostaurin $50 \mathrm{mg}$ twice daily for 6 days and a single dose on day 7 .

CGP52421, the predicted and observed GMRs were 0.6 and 1.2 for AUC and 0.4 and 0.5 for $C_{\max }$, respectively. For CGP62221, the predicted and observed GMRs were 0.6 and 1.0 for AUC and 0.3 and 0.6 for $C_{\max }$, respectively. When midostaurin was coadministered with rifampicin, the predicted versus observed decrease in GM AUC and $C_{\max }$ for midostaurin was $90 \%$ versus $94 \%$ and $79 \%$ versus $73 \%$,
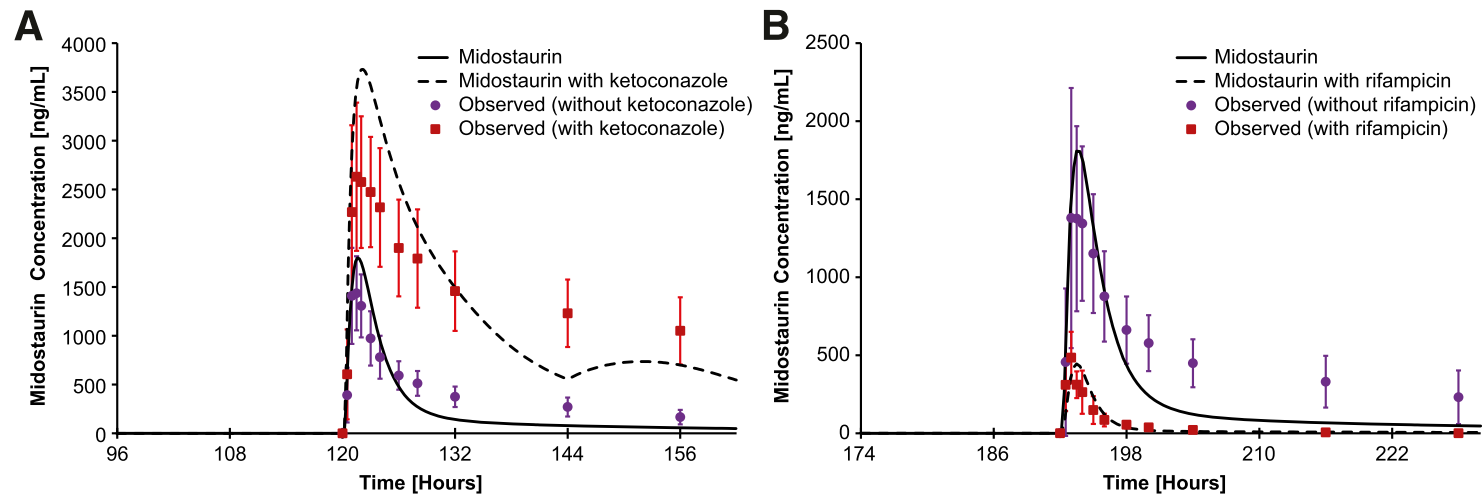

Fig. 2. The simulated mean plasma concentration-time profiles of midostaurin after treatment with midostaurin $50 \mathrm{mg}$ on day 6 in the absence (solid line) or presence (dashed line) of ketoconazole $400 \mathrm{mg}$ once daily on days 1-10 (A) and on day 9 in the absence (solid line) or presence (dashed line) of rifampicin $600 \mathrm{mg}$ once daily on days 1-14 (B). The symbols (with and without interaction are shown in red and purple, respectively) and error bars represent the observed mean plasma concentration-time data and S.D., respectively. 
respectively. The predicted versus observed decrease in GM AUC for CGP52421 was 65\% versus 59\%, respectively, and for CGP622221, $55 \%$ versus $92 \%$, respectively. The corresponding predicted versus observed decrease in GM $C_{\max }$ for CGP52421 and CGP62221 was 9\% versus $35 \%$ and $37 \%$ versus no change, respectively. Overall, the model predicted the exposure change in midostaurin reasonably well when it was coadministered with ketoconazole or rifampicin. However, for its metabolites, there was a trend toward underprediction of exposure change compared with observed data (Table 4).

\section{Simulated DDIs with Moderate and Strong CYP3A4 Inhibitors and Inducers at Steady State in Healthy Subjects and Patients with AML and advSM}

The potential effects of CYP3A4 inhibitors fluconazole (moderate), itraconazole (strong), and ketoconazole (strong) as well as those of CYP3A4 inducers efavirenz (moderate) and rifampicin (strong) on midostaurin exposure at steady-state levels (50 mg twice daily for healthy subjects and patients with AML and $100 \mathrm{mg}$ twice daily for patients with advSM for 28 days) were simulated both in healthy subjects and in patients with AML and advSM.

GMRs of AUC from time zero to the end of the dosing interval at steady-state $\left(\mathrm{AUC}_{0 \text {-tau }}\right) \mathrm{AUC}_{0 \text {-tau }}$ for itraconazole were predicted to be 2.5-, 1.3-, and 1.3-fold for midostaurin, CGP52421, and CGP62221, respectively, using the model for healthy subjects. GMR values of $\mathrm{AUC}_{0 \text {-tau }}$ for ketoconazole DDIs were predicted to be 5.4-, 1.6-, and 1.7fold for midostaurin, CGP52421, and CGP62221, respectively. The results indicated that the impact of DDIs after multiple doses of midostaurin (to steady state) with ketoconazole was similar to the impact of DDIs after a single midostaurin dose (Table 4). GMR values of $\mathrm{AUC}_{0 \text {-tau }}$ for midostaurin with fluconazole were predicted to be 2.7-, 1.6-, and 1.5-fold for midostaurin, CGP52421, and CGP62221, respectively. GMR values of $\mathrm{AUC}_{0 \text {-tau }}$ for rifampicin DDIs were predicted to decrease by $43 \%, 30 \%$, and $25 \%$ for midostaurin, CGP52421, and CGP62221, respectively. The impact of DDIs after multiple doses of midostaurin (to steady state) with rifampicin appears to be less than the impact of DDIs after a single dose of midostaurin (Table 4). With coadministration of efavirenz, GMR values of $\mathrm{AUC}_{0 \text {-tau }}$ were predicted to decrease by $8 \%, 5 \%$, and $4 \%$ for midostaurin, CGP52421, and CGP62221, respectively, suggesting a minimal impact on exposure to midostaurin and its metabolites. The overall prediction results are summarized in the forest plots shown in Fig. 3.

GMR values of $\mathrm{AUC}_{0 \text {-tau }}$ for itraconazole for $\mathrm{AML}$ and $\operatorname{advSM}$ were predicted to be 2.2- and 2.0-fold, 1.0- and 1.2-fold, and 1.2-fold for midostaurin, CGP52421, and CGP62221, respectively, applying the models for patients with AML and advSM. GMR values of $\mathrm{AUC}_{0 \text {-tau }}$ for ketoconazole DDIs for AML and advSM were predicted to be 4.2- and 4.4-fold, 1.1- and 1.5-fold, and 1.5- and 1.6-fold for midostaurin, CGP52421, and CGP62221, respectively. GMR values of $\mathrm{AUC}_{0 \text {-tau }}$ for midostaurin with fluconazole for AML and advSM were predicted to be 2.5- and 2.6-fold, 1.2- and 1.6-fold, and 1.5- and 1.6-fold for midostaurin, CGP52421, and CGP62221, respectively. GMR values of $\mathrm{AUC}_{0 \text {-tau }}$ for rifampicin DDIs for AML and advSM were predicted to decrease by $27 \%$ and $34 \% \%, 13 \%$ and $24 \%$, and $21 \%$ and $20 \%$ for midostaurin, CGP52421, and CGP62221, respectively. With coadministration of efavirenz, GMR values of $\mathrm{AUC}_{0 \text {-tau }}$ were predicted to decrease by $5 \%$ and $3 \%, 1 \%$ and $2 \%$, and $3 \%$ and $2 \%$ for midostaurin, CGP52421, and CGP62221, respectively. The overall prediction results are summarized in the forest plots shown in Fig. 3.

\section{Simulated Hepatic CYP3A4 Dynamics After Treatment with CYP3A4 Inhibitors and Inducers}

From a victim DDI perspective, the model reasonably predicted the observed changes in midostaurin exposure with ketoconazole and rifampicin. The qualified model for healthy subjects was then applied to predict the DDI effect with ketoconazole or rifampicin at steady-state levels. In the presence of a strong CYP3A4 inducer (rifampicin $600 \mathrm{mg}$ daily), the ratios (relative to the control arm) of maximal increased hepatic CYP3A4 activity were 4.9 and 1.9 after a single dose and twice daily dosing of midostaurin (steady state), respectively (Fig. 4A). These ratios are consistent with predicted reductions of midostaurin exposure by $90 \%$ (single dose) and $43 \%$ (steady state) due to the change in CYP3A4 enzyme activity. Conversely, in the presence of a strong CYP3A4 inhibitor (ketoconazole $400 \mathrm{mg}$ daily), the ratios (relative to the control arm) of maximal increased hepatic CYP3A4 activity were 1.08 and 1.02 after a single dose and twice-daily dosing of midostaurin (steady state), respectively (Fig. 4B). These ratios are consistent with predicted similar increases of midostaurin exposure by 5.8-fold (single dose) and 5.4-fold (steady state) due to the similar change in CYP3A4 enzyme activity.

\section{Simulated and Observed DDIs with CYP3A4 Substrate Midazolam}

The clinical combination trial for a single dose of midazolam (4 mg) with a single dose of midostaurin ( $100 \mathrm{mg}$ on day 1 , followed by $50 \mathrm{mg}$ twice daily on days 2-4) was simulated according to the clinical trial design. The effect of midostaurin on midazolam $\mathrm{AUC}_{0 \text {-inf }}$ was predicted to be 1.2-fold (observed, 1.0-fold) and 0.74-fold (observed, 0.95-fold)

TABLE 4

Summary of predicted and observed AUC and $C_{\max }$ ratios with ketoconazole and rifampicin

\begin{tabular}{|c|c|c|c|c|}
\hline & \multicolumn{2}{|c|}{$\mathrm{AUC}_{0^{-}}-20 \mathrm{~h}$ GMR ( $90 \%$ CI range) } & \multicolumn{2}{|c|}{$C_{\max }$ GMR $(90 \%$ CI range) } \\
\hline & Observed & Predicted & Observed & Predicted \\
\hline \multicolumn{5}{|c|}{ With coadministration of ketoconazole ${ }^{a}$} \\
\hline Midostaurin & $6.1(5.0-7.5)$ & $5.8(5.1-6.5)$ & $1.8(1.6-2.1)$ & $2.1(1.9-2.2)$ \\
\hline CGP52421 & $1.2(1.0-1.5)$ & $0.6(0.5-0.7)$ & $0.5(0.4-0.6)$ & $0.4(0.4-0.4)$ \\
\hline \multirow[t]{3}{*}{ CGP62221 } & $1.0(0.8-1.2)$ & $0.6(0.6-0.7)$ & $0.6(0.5-0.7)$ & $0.3(0.3-0.3)$ \\
\hline & \multicolumn{2}{|c|}{$\mathrm{AUC}_{0}-144 \mathrm{~h}$ GMR (90\% CI range) } & \multicolumn{2}{|c|}{$C_{\max }$ GMR (90\% CI range) } \\
\hline & Observed & Predicted & Observed & Predicted \\
\hline \multicolumn{5}{|c|}{ With coadministration of rifampicin $b$} \\
\hline Midostaurin & $0.06(0.05-0.07)$ & $0.10(0.09-0.12)$ & $0.27(0.23-0.31)$ & $0.21(0.18-0.25)$ \\
\hline CGP52421 & $0.41(0.36-0.46)$ & $0.35(0.31-0.40)$ & $0.65(0.59-0.72)$ & $0.91(0.84-0.99)$ \\
\hline CGP62221 & $0.08(0.06-0.09)$ & $0.45(0.40-0.50)$ & $0.63(0.56-0.70)$ & $1.02(0.97-1.09)$ \\
\hline
\end{tabular}

$\mathrm{AUC}_{0-20 \mathrm{~h}}$, AUC over 0-20 h; $\mathrm{AUC}_{0-144 \mathrm{~h}}$, AUC over 0-144 h; CI, confidence interval.

${ }^{a}$ Dose: $400 \mathrm{mg}$ daily on Days $1-10+$ midostaurin $50 \mathrm{mg}$ on Day 6.

${ }^{b}$ Dose: $600 \mathrm{mg}$ daily on Days $1-14+$ midostaurin $50 \mathrm{mg}$ on Day 9 
A

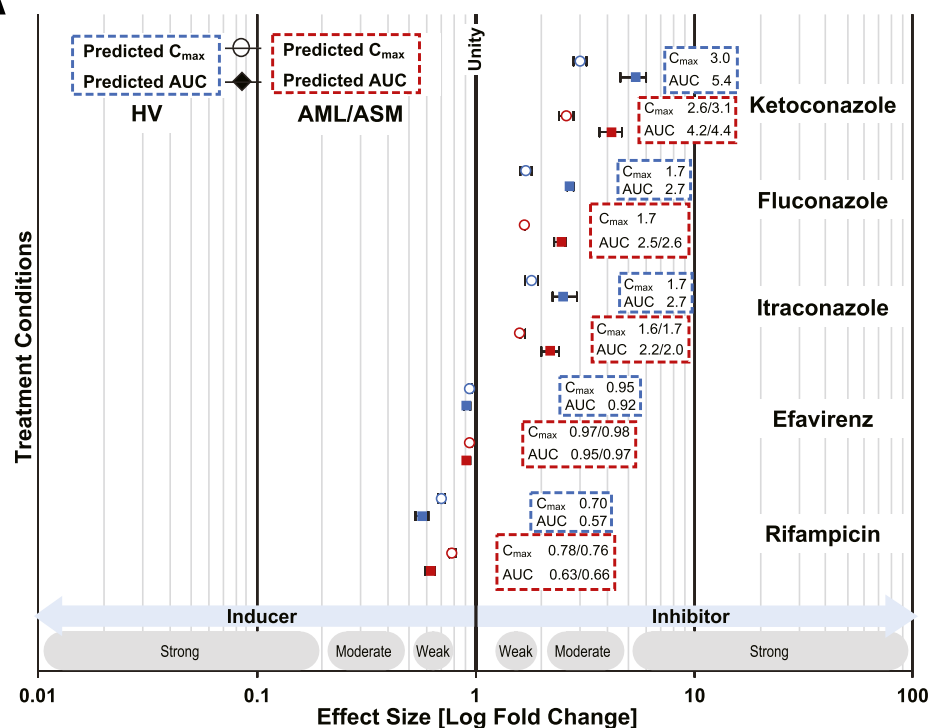

B

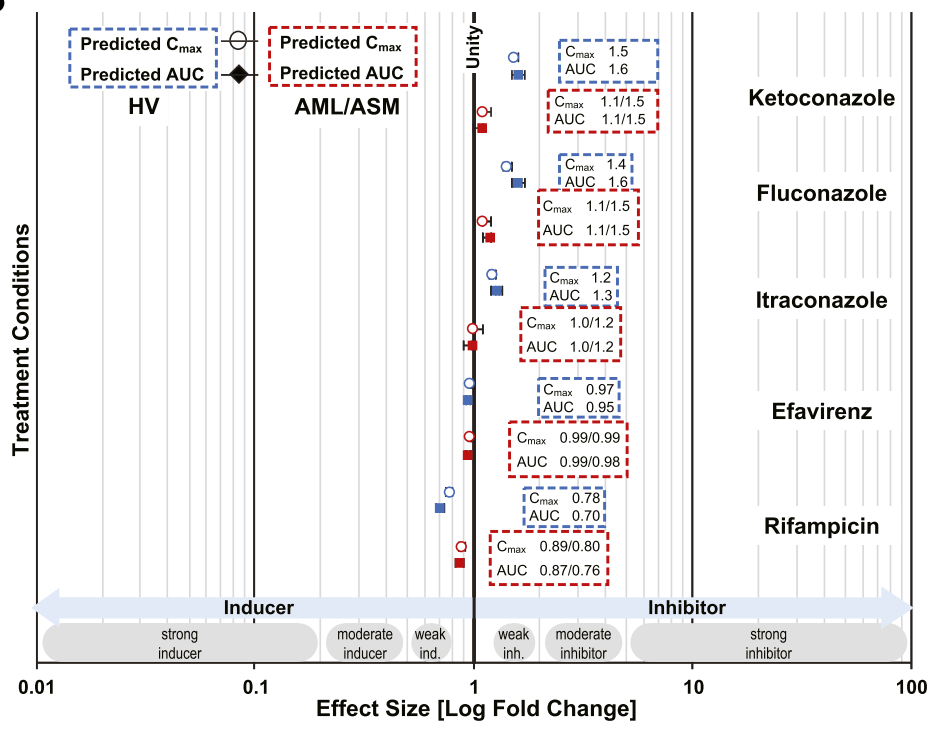

Fig. 3. Simulated AUC and $C_{\max }$ ratios (with $90 \%$ confidence intervals) in healthy volunteers (HVs) and in patients with AML and advSM for midostaurin (A), CGP52421 (B), and CGP62221 (C) when coadministered with ketoconazole, itraconazole, fluconazole, efavirenz, and rifampicin. The open circles and closed squares represent GM $C_{\max }$ and AUC ratios, respectively.

\section{C}

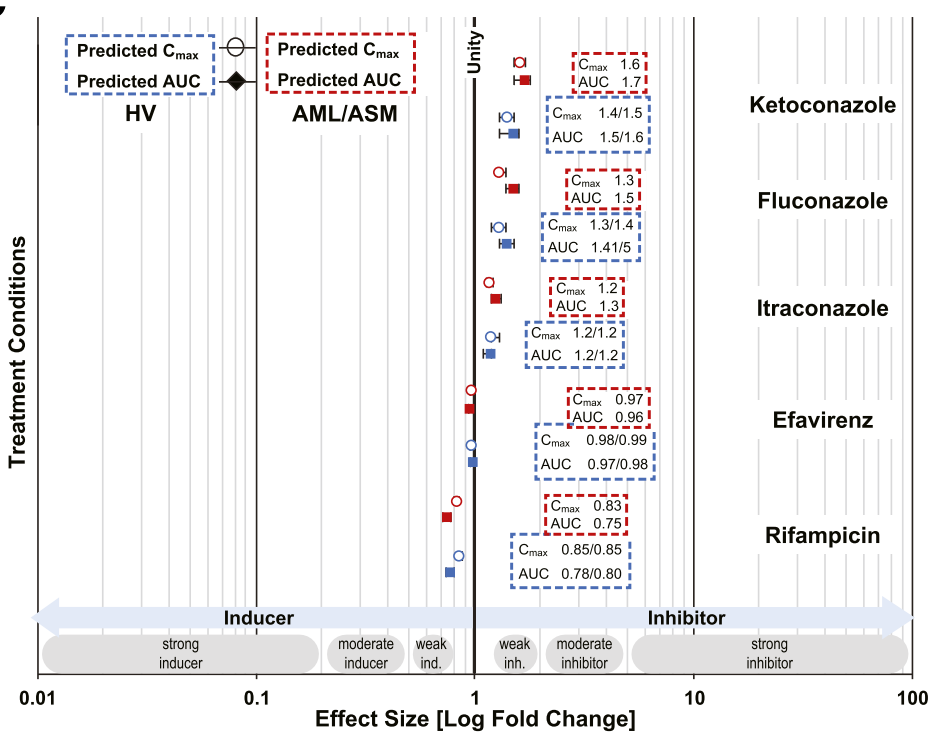



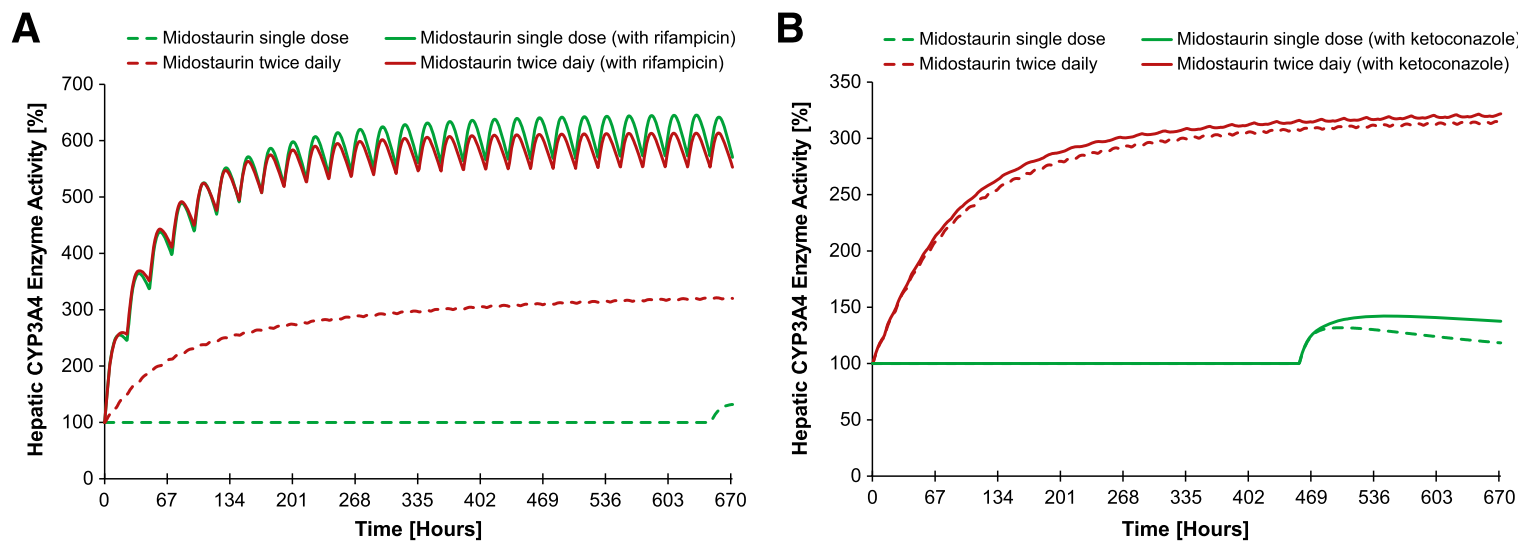

Fig. 4. (A) The solid green and red lines represent the simulated CYP3A4 hepatic activity (percentage of baseline) after a 50-mg single dose and a 50-mg twice-daily dose of midostaurin to steady state (day 28), respectively, after treatment with rifampicin $600 \mathrm{mg}$ once daily. (B) The solid green and red lines represent the simulated CYP3A4 hepatic activity (percentage of baseline) after a 50-mg single dose and a 50-mg twice-daily dose of midostaurin to steady state (day 28), respectively, after treatment with ketoconazole $400 \mathrm{mg}$ once daily.

on days 1 and 6, respectively. The corresponding change in midazolam $C_{\max }$ was predicted to be 1.2 -fold (observed, 0.8-fold) and 1-fold (observed, 0.9-fold), respectively. These results indicated that no CYP3A4 induction effect could be detected in a relatively short study duration. The study duration was short due to safety concerns for healthy subjects. The observed and simulated plasma concentration-time profiles are presented in Fig. 5.

\section{Simulated DDIs with CYP3A4 Substrate Midazolam at Steady State in Healthy Subjects and Patients with AML and advSM}

Simcyp Simulation. The potential interaction of midostaurin with the sensitive CYP3A4 substrate midazolam under steady-state midostaurin dosing conditions was simulated in both healthy subjects and patients with AML and advSM. With coadministration of midostaurin (50 mg twice daily in healthy subjects) to steady state (i.e., 28 days), midazolam $\mathrm{AUC}_{\mathrm{inf}}$ and $C_{\max }$ ratios (relative to dose alone) were predicted to be 0.59 (decreased by $41 \%$ ) and 0.78 (decreased by 22\%), respectively (Fig. 6). The net decrease in midazolam exposure $\left(\mathrm{AUC}_{\mathrm{inf}}\right)$ in the presence of midostaurin (50 or $100 \mathrm{mg}$ twice daily in AML and advSM, respectively) relative to dose alone was predicted to be 0.60 and 0.54 , respectively. Overall, this would be indicative of an induction effect of midostaurin and its metabolites at steady state.

Assessment of CYP3A4 Activity Using Plasma Biomarker $4 \beta \mathrm{HC}$ Levels. At baseline, the GM $4 \beta \mathrm{HC}$ levels were similar among the negative control arm, the positive control arm, and the midostaurin arm despite the absence of global randomization (Table 5).

In the negative control arm (subjects receiving placebo), $4 \beta \mathrm{HC}$ levels remained stable on days 9,11 , and 15 . No time dependency in levels was observed. In contrast, $4 \beta \mathrm{HC}$ levels notably increased over time in the positive control arm (subjects treated with rifampicin) on days 9, 11, and 15.

In the midostaurin arm ( $100 \mathrm{mg}$ twice daily), $4 \beta \mathrm{HC}$ levels moderately increased ( $\sim 1.8$-fold) until day 15 , at which point they had approximately doubled relative to baseline. The $4 \beta \mathrm{HC}$ levels remained constant from day 15 to PK steady state of midostaurin (day 28) (Fig. 7). GM $4 \beta \mathrm{HC}$ levels on days $3,8,9,11,15,22$, and 28 are presented (Table 5). A net increase in plasma $4 \beta \mathrm{HC}$ levels was observed with midostaurin (100 mg twice daily) under steady-state conditions, also suggesting an induction effect of midostaurin and its metabolites at steady state. In the rifampicin arm (positive control), the $4 \beta \mathrm{HC}$ levels increased 3.2-, 3.5-, and 4.3 -fold on days 9,11 , and 15 , respectively.

\section{Discussion}

In the current study, we present a case example using a PBPK modeling approach to predict the DDIs associated with a mixed net effect (TDI and induction) on CYP3A4 for the parent compound as well as its two major circulating metabolites in healthy subjects and in patients with AML and advSM.

In our modeling approach, in vitro study-determined parameters (Supplemental Material) were initially used. However, the simulated concentration-time profiles after multiple dosing showed net autoinhibition (data not shown) rather than observed auto-induction. Subsequently, $\mathrm{EC}_{50}$ values were optimized (20-fold more potent for all three components) based on the fitting of single- and multiple-dosing PK profiles from clinical PK and DDI trials. The underprediction in induction magnitude using in vitro data could be due to other mechanisms involved in the induction of CYP3A4 mRNA. For example, CYP3A4 could be induced through P53 protein activation and may be relevant for patients with cancer (Harmsen et al., 2009; Elias et al., 2013; Goldstein et al., 2013); tyrosine kinase inhibitors may potentially induce CYP3A4 mRNA involving CAR1 and P53 (Lin et al., 2016). Because the induction was ultimately modeled using a "top-down" approach for midostaurin and its metabolites, any other potential mechanisms of CYP3A4 regulation would be captured in the model. Although a more extensive data set was required, this model is considered to be mechanistic because it allows for the incorporation of changes in CL of midostaurin as a result of its auto-inhibition/induction after multiple dosing. By using the middle-out approach (combining top-down and bottom-up approaches), the model could reasonably capture the acute effects of auto-inhibition and subsequent auto-induction, as predicted by increased exposure of midostaurin on day 7 relative to day 1 followed by a decreasing trend in exposure on day 28 . The half-life and time to steady state were taken into account, and a standard dosing regimen $(50 \mathrm{mg}$ twice daily for healthy subjects and patients with AML and $100 \mathrm{mg}$ twice daily for patients with advSM for 28 days) was consistently used to closely mimic a potential clinical, steady-state dosing regimen. The model was then used to simulate the PK profiles of midostaurin and its metabolites at steady state and predict the subsequent effects on midazolam exposure. 

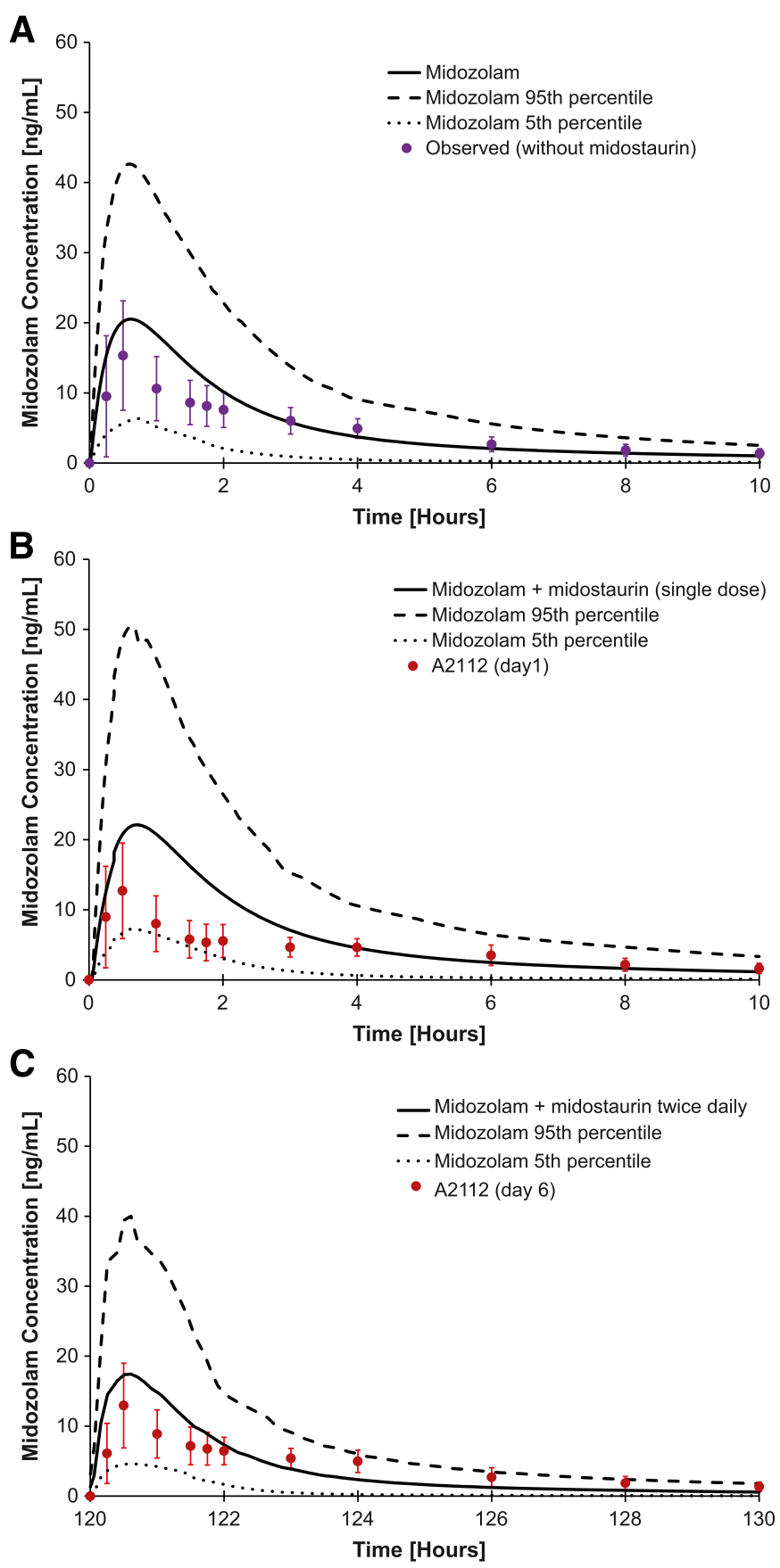

Fig. 5. The solid lines represent the simulated mean systemic plasma concentrationtime profiles of midazolam $4 \mathrm{mg}$ in the absence of midostaurin (A), with a single dose of midostaurin $100 \mathrm{mg}$ on day 1 (B), and with an additional twice-daily dose of midostaurin $50 \mathrm{mg}$ on days $2-4(\mathrm{C})$. The dashed lines represent the simulated lower 5 th and upper 95th percentiles. The symbols (with and without interaction are shown in red and purple, respectively) and error bars represent the observed mean plasma concentration-time data and S.D., respectively.

Per regulatory guidance (European Medicines Agency, 2012; Food and Drug Administration, 2012), the simulated midazolam AUC ratio is consistent with the classification of midostaurin as a weak CYP3A4 inducer (20\%-50\% decrease in AUC). The simulated net effect of midostaurin and its metabolites as a weak CYP3A4 inducer was also supported by changes in plasma $4 \beta \mathrm{HC}$, an emerging biomarker of CYP3A4 activity (Bodin et al., 2001; Bjorkhem-Bergman et al., 2013; Leil et al., 2014). The net effect was an increase in observed $4 \beta \mathrm{HC}$, suggesting CYP3A4 induction. Based on the relationships among midazolam AUC GMR, rifampicin dose, and plasma $4 \beta \mathrm{HC}$ level, a framework has been developed recently to classify the CYP3A4 inducer potencies of new chemical entities after 14 days of dosing (Mangold et al., 2016). Using this framework (although not accepted currently by regulatory authorities) and considering the observed increase in plasma $4 \beta \mathrm{HC}$ in our study (maximal 2-fold increase), midostaurin $(100 \mathrm{mg}$ twice daily for 28 days) could be viewed as a moderate CYP3A4 inducer in the worst-case scenario. One caveat to using the plasma $4 \beta \mathrm{HC}$ biomarker is that the potency classification can be dependent on sample size. Based on the low variability of $4 \beta \mathrm{HC}$, it is theorized that for a strong inducer such as rifampicin, there would be at least an $80 \%$ probability of detecting a $4 \beta \mathrm{HC}$ elevation with a sample size of $<10$. For detecting moderate and weak inducers, the approximate sample size would be $n=10-25$ and $n>60$, respectively (Leil et al., 2014). Given that the $4 \beta \mathrm{HC}$ data with midostaurin are based on only 10 patients, the classification of midostaurin as a weak to moderate CYP3A4 inducer is, at best, supportive of the PBPK modeling results and needs further confirmation using a larger sample size. Nonetheless, the $4 \beta \mathrm{HC}$ biomarker data provided an additional tool to evaluate the net effect of CYP3A4 induction or inhibition by midostaurin and its metabolites at steady state when midostaurin was coadministered with midazolam and increased our confidence in the DDI predictions.

To evaluate the victim DDI potential of midostaurin, the CYP3A4 activity after single and multiple doses of midostaurin needs to be considered. The change in simulated CYP3A4 activity with midostaurin alone and in combination with ketoconazole was similar in both singleand multiple-dose scenarios (Fig. 4B). Based on this observation, CYP3A4 inhibitors are predicted to have a similar impact on midostaurin exposure under single- and multiple-dose conditions.

However, the DDI predictions in the presence of CYP3A4 inducers were found to be highly dependent on single- versus multiple-dose conditions. As expected, CYP3A4 activity was not significantly affected by single-dose midostaurin, but it increased upon multiple dosing. Consequently, when another CYP3A4 inducer (rifampicin) was coadministered, the net increase in CYP3A4 activity was less with a single dose than with multiple midostaurin doses, resulting in a $90 \%$ decrease in midostaurin exposure under single-dose conditions versus a $43 \%$ decrease under multiple-dose conditions. For these reasons, efavirenz (a moderate CYP3A4 inducer) was predicted to have a minimal impact on midostaurin exposure at steady state (i.e., a decrease of $8 \%$ ).

It is noticed that the predicted increase in the AUC of midostaurin after coadministration of itraconazole $100 \mathrm{mg}$ twice daily was lower than that with ketoconazole $400 \mathrm{mg}$ daily. This is likely in part due to the metabolism of itraconazole as a CYP3A4 substrate being affected by midostaurin and its metabolites, resulting in the induction of CYP3A4 activity. The exposure of itraconazole in the presence of midostaurin was predicted to be lower than for itraconazole administered alone, and the inhibitory effect of itraconazole metabolites appears to be less potent than that of itraconazole alone.

Our simultaneous PBPK modeling approach takes the first step toward assessing the complex CYP3A4 DDI potential of a parent drug and its two metabolites in healthy subjects. To assess the DDI potential of other CYP3A4 inhibitors/inducers used routinely in patients with cancer, two additional PBPK models were built for patients with AML and advSM. Patients with cancers are different than healthy subjects in terms of demographic and physiologic properties. Moreover, the Pop of patients with cancer is heterogeneous, and the differences in various characteristics for patients with cancer, as well as different types of cancer (e.g., AML and advSM), can affect the ADME and PK of drugs. To fully characterize physiologic differences between healthy subjects and patients with cancer, the development of a cancer Pop file has been 

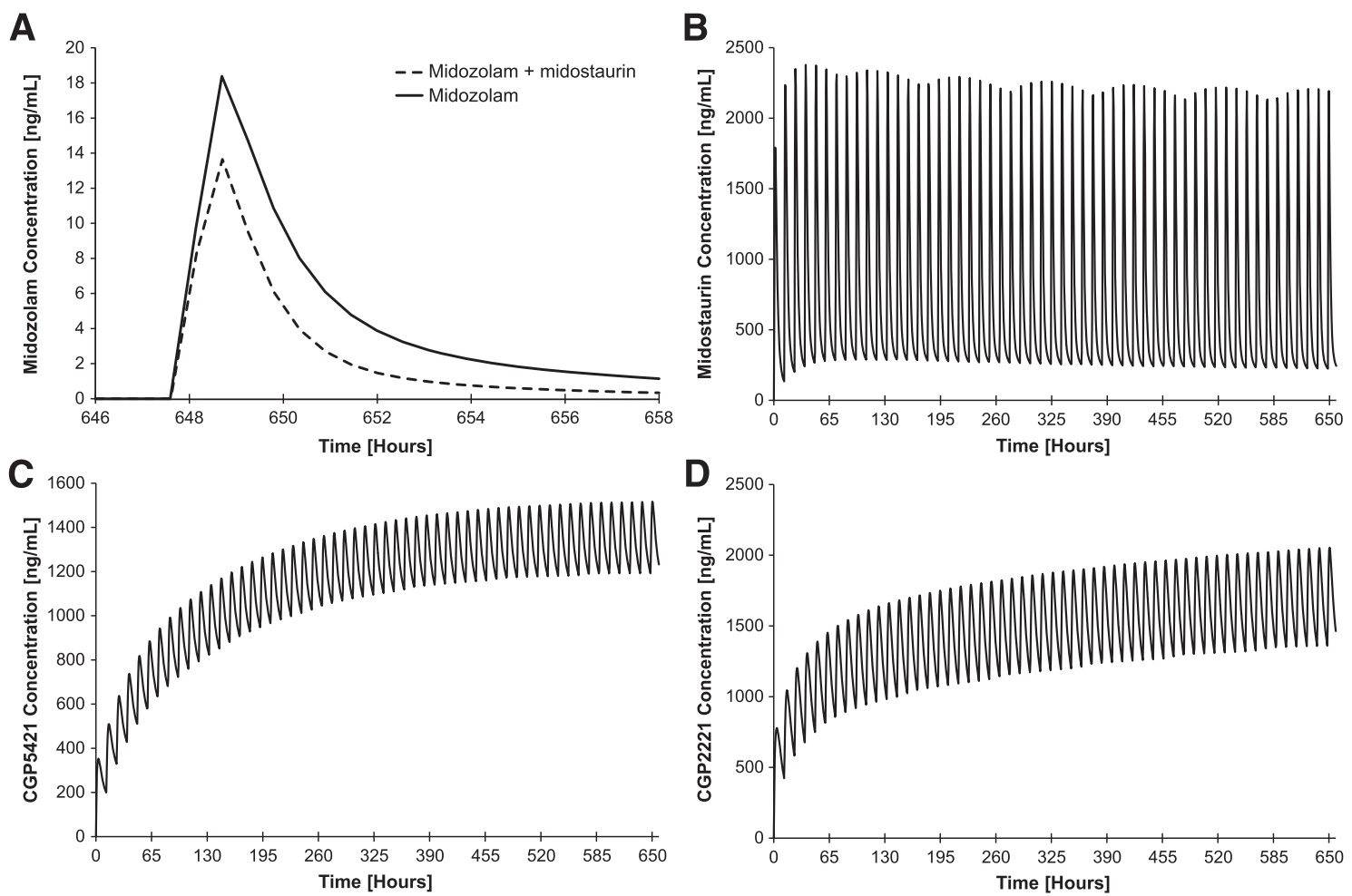

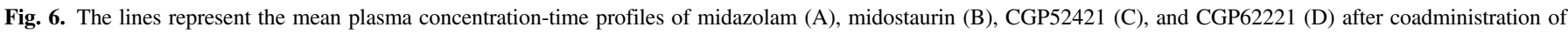
midazolam $4 \mathrm{mg}$ and midostaurin $50 \mathrm{mg}$ twice daily for 28 days.

shown to be a promising tool for the prediction of PK in patients (Cheeti et al., 2013). However, development, validation, and application of cancer-specific profiles will require more comprehensive data collection. Due to the limited knowledge and understanding of the mechanisms of the PK differences observed in healthy subjects and patients with cancer, two individual compound files were built for patients with AML and patients with advSM; the lower $\mathrm{V}_{\text {ss }}$ and $\mathrm{CL}_{\text {int }}$ values of midostaurin for patients with both cancer and lower CL of CGP52421 for AML compared with the model for healthy subjects were applied to the patient models. Lower CL values of midostaurin and CGP52421 in patients with AML than in healthy subjects are likely due to multiple factors. The mechanism of the differences in these parameters is not clear; however, it may be a difference in midostaurin distribution (although similar plasma protein binding between healthy subjects and patients was observed in ex vivo studies) and metabolic CL between the two Pops. It could also be that the metabolic CL of CGP52421 in patients with AML is different than that in healthy subjects and patients with advSM. In recent years, researchers have suggested that circulating levels of cytokines, including interleukin-6 (IL-6), are significantly higher in patients with AML than in healthy subjects (Meyers et al., 2005; Tsimberidou et al., 2008). Furthermore, the suppression of CYP3A4 by IL-6 in hepatocytes was observed and clinical examples

TABLE 5

Geometric mean $4 \beta \mathrm{HC}$ plasma levels at each time point

\begin{tabular}{|c|c|c|c|}
\hline & Negative Control $(n=20)$ & Positive Control $(n=20)$ & $\operatorname{Midostaurin}(n=10 ; 4$ males and 6 females) \\
\hline \multicolumn{4}{|c|}{$\mathrm{GM} 4 \beta \mathrm{HC}$ plasma levels, $\mathrm{CV} \%(\mathrm{ng} / \mathrm{ml})$} \\
\hline Baseline (day 1) & $25.3(35.5)$ & $22.0(44.0)$ & $29.2(43.7)$ \\
\hline Day 3 & N.A. & N.A. & $34.1(43.7)$ \\
\hline Day 8 & N.A. & N.A. & $41.7(39.1)$ \\
\hline Day 9 & $23.4(36.4)$ & $75.0(32.1)$ & N.A. \\
\hline Day 11 & $25.4(35.9)$ & $89.5(33.5)$ & N.A. \\
\hline Day 15 & $23.3(38.8)$ & $102.7(27.6)$ & $53.8(34.7)$ \\
\hline Day 22 & N.A. & N.A. & $51.4(37.1)$ \\
\hline Day 28 & N.A. & N.A. & $56.0(35.6)$ \\
\hline \multicolumn{4}{|c|}{$\begin{array}{l}\text { GM percentage change in } 4 \beta \mathrm{HC} \text { plasma levels from baseline, } \\
\qquad \mathrm{CV} \%(\%)\end{array}$} \\
\hline Day 3 & N.A. & N.A. & $16.8(0.1)$ \\
\hline Day 8 & N.A. & N.A. & $42.9(-10.3)$ \\
\hline Day 9 & $-7.7(102)$ & $240.3(-26.9)$ & N.A. \\
\hline Day 11 & $0.4(101)$ & $306.0(-23.9)$ & N.A. \\
\hline Day 15 & -8.1 (109) & $366.1(-37.3)$ & $84.2(-20.6)$ \\
\hline Day 22 & N.A. & N.A. & $76.1(-14.9)$ \\
\hline Day 28 & N.A. & N.A. & $91.7(18.4)$ \\
\hline
\end{tabular}

N.A., not applicable. 


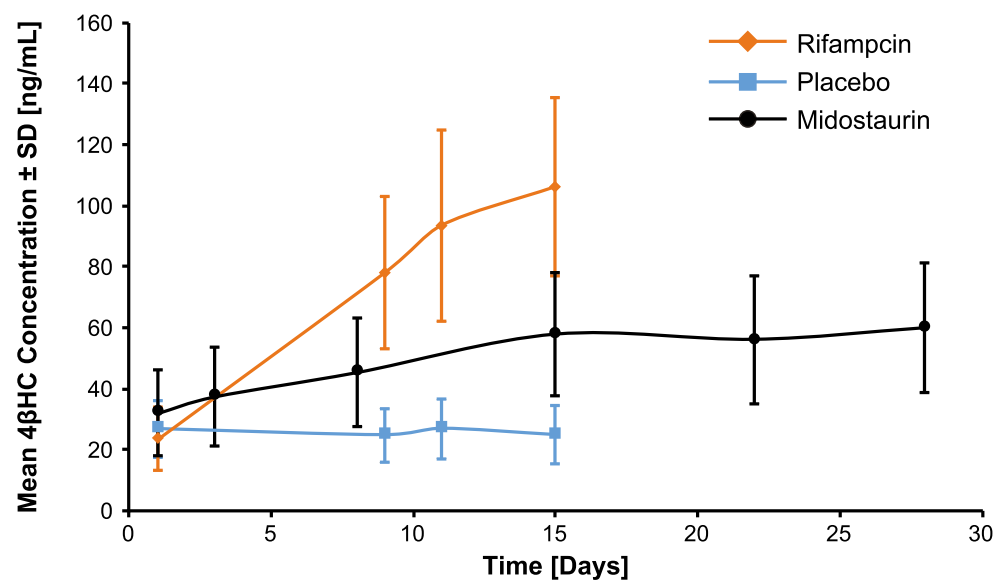

Fig. 7. Overlays of measured $4 \beta \mathrm{HC}$ profiles with ratios relative to baseline and predicted changes in midazolam AUC ratios affected by midostaurin and its metabolites. Midostaurin, patients with advSM who received midostaurin $100 \mathrm{mg}$ twice daily on days $1-28$; Negative control, healthy volunteers who received placebo on days $1-15$ and midostaurin on day 9 . Positive control, healthy volunteers who received rifampicin $600 \mathrm{mg}$ once daily on days $1-15$ and midostaurin on day 9.

\begin{tabular}{lccccc}
\hline Time [Days] & $\mathbf{3}$ & $\mathbf{8}$ & $\mathbf{1 5}$ & $\mathbf{2 2}$ & $\mathbf{2 8}$ \\
\hline $\begin{array}{l}\text { Predicted midazolam GM AUC } \\
\text { ratio with midostaurin }\end{array}$ & 0.84 & 0.60 & 0.55 & 0.54 & 0.54 \\
$\begin{array}{l}\text { Plasma 4BHC GM ratio } \\
\text { relative to baseline }\end{array}$ & 1.2 & 1.4 & 1.8 & 1.8 & 1.9 \\
\hline
\end{tabular}

have been reported showing that CYP3A4-mediated metabolism was affected by cytokine modulators (e.g., elevation of IL-6 level), resulting in reduced CYP3A4 expression (Evers et al., 2013). In addition, a lower $F_{a}$ value of midostaurin than those in the healthy subject model was used for the advSM model. The reduced overall absorption in patients with advSM could be due to the disease-related abnormal numbers of mast cells in organs, including the gastrointestinal tract (Cardet et al., 2013), which may affect oral absorption.

In conclusion, the PBPK model described here using a middle-out approach reasonably predicted PK profiles of midostaurin and its two metabolites after single and multiple dosing. The simultaneous parent and metabolite modeling approach allowed predictions under steady-state conditions that were not possible to achieve in healthy subjects. The model also captured the apparent effect of mixed TDI/induction mechanisms. Our combined, multipronged approach allowed the extension of findings from single-dose clinical DDI studies and enabled predictions of steadystate DDI effects to be made with improved confidence. The results generated using this integrated approach provide the support of clinical recommendations and potential product label language.

\section{Acknowledgments}

We thank statistician Matthieu Villeneuve, a former employee of Novartis, for data analysis of $4 \beta \mathrm{HC}$. We also thank Jennifer Gooch and Pamela Tuttle, CMPP, of ArticulateScience LLC, for medical editorial assistance.

\section{Authorship Contributions}

Participated in research design: Gu, Dutreix, Einolf, and He.

Conducted experiments: Gu, Wang, and Chun.

Performed data analysis: Gu and Dutreix.

Wrote or contributed to the writing of the manuscript: Gu, Dutreix, Rebello, Ouatas, Einolf, and He.

\section{References}

Andrejauskas-Buchdunger E and Regenass U (1992) Differential inhibition of the epidermal growth factor-, platelet-derived growth factor-, and protein kinase C-mediated signal transduction pathways by the staurosporine derivative CGP 41251. Cancer Res 52:5353-5358.

Barry EV, Clark JJ, Cools J, Roesel J, and Gilliland DG (2007) Uniform sensitivity of FLT3 activation loop mutants to the tyrosine kinase inhibitor midostaurin. Blood 110:4476-4479.

Björkhem-Bergman L, Bäckström T, Nylén H, Rönquist-Nii Y, Bredberg E, Andersson TB Bertilsson L, and Diczfalusy U (2013) Comparison of endogenous 4 $\beta$-hydroxycholesterol with midazolam as markers for CYP3A4 induction by rifampicin. Drug Metab Dispos 41:1488-1493.
Bodin K, Bretillon L, Aden Y, Bertilsson L, Broomé U, Einarsson C, and Diczfalusy U (2001) Antiepileptic drugs increase plasma levels of 4beta-hydroxycholesterol in humans: evidence for involvement of cytochrome p450 3A4. J Biol Chem 276:38685-38689.

Cardet JC, Akin C, and Lee MJ (2013) Mastocytosis: update on pharmacotherapy and future directions. Expert Opin Pharmacother 14:2033-2045.

Cheeti S, Budha NR, Rajan S, Dresser MJ, and Jin JY (2013) A physiologically based pharmacokinetic (PBPK) approach to evaluate pharmacokinetics in patients with cancer. Biopharm Drug Dispos 34:141-154.

Diczfalusy U, Nylén H, Elander P, and Bertilsson L (2011) 4 $\beta$-Hydroxycholesterol, an endogenous marker of CYP3A4/5 activity in humans. Br J Clin Pharmacol 71:183-189.

Dutreix C, Munarini F, Lorenzo S, Roesel J, and Wang Y (2013) Investigation into CYP3A4 mediated drug-drug interactions on midostaurin in healthy volunteers. Cancer Chemother Pharmacol 72:1223-1234.

Dutreix C, Lorenzo S, and Wang Y (2014) Comparison of two endogenous biomarkers of CYP3A4 activity in a drug-drug interaction study between midostaurin and rifampicin. Eur J Clin Pharmacol 70:915-920.

Elias A, Wu J, and Chen T (2013) Tumor suppressor protein p53 negatively regulates human pregnane X receptor activity. Mol Pharmacol 83:1229-1236.

Evers R, Dallas S, Dickmann LJ, Fahmi OA, Kenny JR, Kraynov E, Nguyen T, Patel AH, Slatter JG, and Zhang L (2013) Critical review of preclinical approaches to investigate cytochrome P450-mediated therapeutic protein drug-drug interactions and recommendations for best practices: a white paper. Drug Metab Dispos 41:1598-1609.

European Medicines Agency (EMA) (2012) Committee for Human Medicinal Products (CHMP Guideline on the investigation of drug interactions. June 21, 2012. European Medicines Agency, London.

Fabbro D, Ruetz S, Bodis S, Pruschy M, Csermak K, Man A, Campochiaro P, Wood J, O'Reilly T, and Meyer T (2000) PKC412-a protein kinase inhibitor with a broad therapeutic potential. Anticancer Drug Des 15:17-28.

Fahmi OA, Hurst S, Plowchalk D, Cook J, Guo F, Youdim K, Dickins M, Phipps A, Darekar A, Hyland R, et al. (2009) Comparison of different algorithms for predicting clinical drug-drug interactions, based on the use of CYP3A4 in vitro data: predictions of compounds as precipitants of interaction. Drug Metab Dispos 37:1658-1666.

Food and Drug Administration (2012) Drug Interaction Studies-Study Design, Data Analysis, Implications for Dosing, and Labeling Recommendations: Guidance for Industry, US Department of Health and Human Services, Food and Drug Administration, Center for Drug Evaluation and Research, Center for Veterinary Medicine, Rockville, MD.

Fenneteau F, Poulin P, and Nekka F (2010) Physiologically based predictions of the impact of inhibition of intestinal and hepatic metabolism on human pharmacokinetics of CYP3A substrates. J Pharm Sci 99:486-514.

Fischer T, Stone RM, Deangelo DJ, Galinsky I, Estey E, Lanza C, Fox E, Ehninger G, Feldman EJ, Schiller GJ, et al. (2010) Phase IIB trial of oral Midostaurin (PKC412), the FMS-like tyrosine kinase 3 receptor (FLT3) and multi-targeted kinase inhibitor, in patients with acute myeloid leukemia and highrisk myelodysplastic syndrome with either wild-type or mutated FLT3. J Clin Oncol 28:4339-4345.

Gallogly MM and Lazarus HM (2016) Midostaurin: an emerging treatment for acute myeloid leukemia patients. J Blood Med 7:73-83

Garg V, Chandorkar G, Farmer HF, Smith F, Alves K, and van Heeswijk RP (2012) Effect of telaprevir on the pharmacokinetics of midazolam and digoxin. J Clin Pharmacol 52:1566-1573.

Goldstein I, Rivlin N, Shoshana OY, Ezra O, Madar S, Goldfinger N, and Rotter V (2013) Chemotherapeutic agents induce the expression and activity of their clearing enzyme CYP3A4 by activating p53. Carcinogenesis 34:190-198.

Gotlib J, Berubé C, Growney JD, Chen CC, George TI, Williams C, Kajiguchi T, Ruan J, Lilleberg SL, Durocher JA, et al. (2005) Activity of the tyrosine kinase inhibitor PKC412 in a patient with mast cell leukemia with the D816V KIT mutation. Blood 106:2865-2870.

Gotlib J, Kluin-Nelemans HC, George TI, Akin C, Sotlar K, Hermine O, Awan FT, Hexner E, Mauro MJ, Sternberg DW, et al. (2016) Efficacy and safety of midostaurin in advanced systemic mastocytosis. N Engl J Med 374:2530-2541. 
Harmsen S, Meijerman I, Beijnen JH, and Schellens JH (2009) Nuclear receptor mediated induction of cytochrome P450 3A4 by anticancer drugs: a key role for the pregnane $\mathrm{X}$ receptor. Cancer Chemother Pharmacol 64:35-43.

He H, Tran P, Gu H, Tedesco V, Zhang J, Lin W, Gatlik E, Klein K, and Heimbach T (2017) Midostaurin, a novel protein kinase inhibitor for the treatment of acute myelogenous leukemia: insights from human absorption, metabolism, and excretion studies of a BDDCS II drug. Drug Metab Dispos 45:540-555.

Leil TA, Kasichayanula S, Boulton DW, and LaCreta F (2014) Evaluation of 4betahydroxycholesterol as a clinical biomarker of CYP3A4 drug interactions using a Bayesian mechanism-based pharmacometric model. CPT Pharmacometrics Syst Pharmacol 3:e120.

Levis M, Brown P, Smith BD, Stine A, Pham R, Stone R, Deangelo D, Galinsky I, Giles F, Estey E, et al. (2006) Plasma inhibitory activity (PIA): a pharmacodynamic assay reveals insights into the basis for cytotoxic response to FLT3 inhibitors. Blood 108:3477-3483.

Lin Z, Fahmi OA, Johnson N, Rodrigues DA, Obach RS, Steyn SJ, Zientek M, and Goosen TC (2016) Tyrosine kinase inhibitors robustly induced CYP3A4 mRNA, but not activity via multiple pathways, in 21st International Symposium on Microsomes and Drug Oxidations; 2016 October 2-6; Davis, CA. International Society for the Study of Xenobiotics, Washington, DC.

Mangold JB, Wu F, and Rebello S (2016) Compelling relationship of CYP3A induction to levels of the putative biomarker $4 \beta$-hydroxycholesterol and changes in midazolam exposure. Clin Pharmacol Drug Dev 5:245-249.

Meyers CA, Albitar M, and Estey E (2005) Cognitive impairment, fatigue, and cytokine levels in patients with acute myelogenous leukemia or myelodysplastic syndrome Cancer 104:788-793.

Propper DJ, McDonald AC, Man A, Thavasu P, Balkwill F, Braybrooke JP, Caponigro F, Graf P, Dutreix C, Blackie R, et al. (2001) Phase I and pharmacokinetic study of PKC412, an inhibitor of protein kinase C. J Clin Oncol 19:1485-1492.

Prueksaritanont T, Chu X, Gibson C, Cui D, Yee KL, Ballard J, Cabalu T, and Hochman J (2013) Drug-drug interaction studies: regulatory guidance and an industry perspective. AAPS J 15 629-645.

Reitman ML, Chu X, Cai X, Yabut J, Venkatasubramanian R, Zajic S, Stone JA, Ding Y, Witter R, Gibson C, et al. (2011) Rifampin's acute inhibitory and chronic inductive drug interactions: experimental and model-based approaches to drug-drug interaction trial design. Clin Pharmacol Ther 89:234-242.
Rowland Yeo K, Walsky RL, Jamei M, Rostami-Hodjegan A, and Tucker GT (2011) Prediction of time-dependent CYP3A4 drug-drug interactions by physiologically based pharmacokinetic modelling: impact of inactivation parameters and enzyme turnover. Eur J Pharm Sci 43:160-173 Stone RM, DeAngelo DJ, Klimek V, Galinsky I, Estey E, Nimer SD, Grandin W, Lebwohl D, Wang Y, Cohen P, et al. (2005) Patients with acute myeloid leukemia and an activating mutation in FLT3 respond to a small-molecule FLT3 tyrosine kinase inhibitor, PKC412. Blood 105: $54-60$.

Stone RM, Mandrekar S, Sandord L, Geyer S, Bloomfield CD, Döhner K, Thiede C, Marcucci G, Lo-Coco F, Klisovic RB, et al. (2015) The multi-kinase inhibitor midostaurin (M) prolongs survival compared with placebo $(\mathrm{P})$ in combination with daunorubicin (D)/cytarabine $(\mathrm{C})$ induction (ind), high-dose $\mathrm{C}$ consolidation (consol), and as maintenance (maint) therapy in newly diagnosed acute myeloid leukemia (AML) patients (pts) age 18-60 with FLT3 mutations (muts): an international prospective randomized (rand) P-controlled double-blind trial (CALGB 10603/ RATIFY [Alliance]). Blood 126:6.

Tsimberidou AM, Estey E, Wen S, Pierce S, Kantarjian H, Albitar M, and Kurzrock R (2008) The prognostic significance of cytokine levels in newly diagnosed acute myeloid leukemia and highrisk myelodysplastic syndromes. Cancer 113:1605-1613.

Wang Y, Yin OQ, Graf P, Kisicki JC, and Schran H (2008) Dose- and time-dependent pharmacokinetics of midostaurin in patients with diabetes mellitus. J Clin Pharmacol 48:763-775.

Weisberg E, Boulton C, Kelly LM, Manley P, Fabbro D, Meyer T, Gilliland DG, and Griffin JD (2002) Inhibition of mutant FLT3 receptors in leukemia cells by the small molecule tyrosine kinase inhibitor PKC412. Cancer Cell 1:433-443.

Weiss HM and Gatlik E (2014) Equilibrium gel filtration to measure plasma protein binding of very highly bound drugs. J Pharm Sci 103:752-759.

Yin OQ, Wang Y, and Schran H (2008) A mechanism-based population pharmacokinetic model for characterizing time-dependent pharmacokinetics of midostaurin and its metabolites in human subjects. Clin Pharmacokinet 47:807-816.

Address correspondence to: Helen Gu, Novartis Pharmaceuticals Corporation, One Health Plaza, East Hanover, NJ 07936. E-mail: helen.gu@novartis.com 